
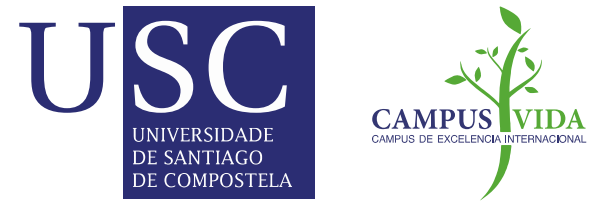

\title{
1D to 2D Self Assembly of Cyclic Peptides
}

Ignacio Insua and Javier Montenegro

\section{Supporting information}

\section{Copyright information:}

(C) 2019 American Chemical Society 


\section{D to 2D Self Assembly of Cyclic Peptides}

Ignacio Insua \& Javier Montenegro*

Centro Singular de Investigación en Química Biolóxica e Materiais Moleculares (CIQUS), Departamento de Química Orgánica, Universidade de Santiago de Compostela, 15782, Spain.

*e-mail: javier.montenegro@usc.es

\section{Table of contents}

1. Materials S2

2. Instrumentation S2

3. Abbreviations S2

4. Synthesis and purification of cyclic peptides S3

5. $\mathbf{C P x}$ characterisation S5

6. CPXAla characterisation S7

7. $\mathbf{C P x}$-Glu characterisation S9

8. $\mathbf{C P x}$-His characterisation S11

9. Epifluorescence microscopy of $\mathbf{C P x}$ nanosheets S13

10. Scanning-transmission electron microscopy (STEM) of CPx nanosheets $S 13$

11. Sonication of $\mathbf{C P x}$ nanosheets: Epifluorescence and electron microscopy S14

12. Annealing of $\mathbf{C P x}$ nanosheets: Electron microscopy S15

13. Annealing of CPx nanosheets: Dynamic light scattering (DLS) S15

14. Exploration of self-assembling conditions of $\mathbf{C P x}$ nanosheets S16

15. Atomic force microscopy (AFM) of CPx nanosheets at $p H 2.8$ 518

16. Dynamic behaviour of $\mathbf{C P x}$ nanosheets in response to $\mathrm{pH}$ and temperature S18

17. FT-IR analysis of CPx nanosheets S19

18. Circular dichroism (CD) analysis of CPx nanosheets S19

19. Imaging of peptide controls (CPxAla, CPx-Glu and CPx-His) S20 


\section{Materials}

All reagents and solvents were purchased from Acros Organics, Aldrich, Fisher Scientific, Iris Biotech and Novabiochem. Dichloromethane was dried under reflux over calcium hydride. Glass slides for fluoresce microscopy were obtained from Ibidi (Cat\# 80827). TEM grids (i. Cu carbon type-B, 300 mesh; ii. Holey carbon, 400 mesh) and PELCO ${ }^{\circledR}$ mica discs for AFM were purchased from Ted Pella.

\section{Instrumentation}

Peptide purification was carried out by preparative reverse-phase HPLC (Waters 1525 and 2489) using an Agilent Eclipse XDB-C18 column. ${ }^{1} \mathrm{H}-\mathrm{NMR}$ spectra were acquired on Varian 300 or $500 \mathrm{MHz}$ spectrometers at $298 \mathrm{~K}$; chemical shifts $(\delta)$ are reported in ppm relative to that of DMSO $(\delta=2.50$ ppm). Analytical UHPLC of the peptide was performed on an Agilent 1260 Infinity II fitted with an Agilent SB-C18 column and connected to a 6120 quadrupole MS detector. HR-MS was acquired on a Bruker MicroTOF. FT-IR spectra were acquired on a PerkinElmer Spectrum II fitted with an ATR. Epifluorescence micrographs were taken with a Nikon Eclipse Ti (60x immersion objective, FITC cube: $E x=475 / 35 \mathrm{~nm} ; E m=530 / 43 \mathrm{~nm}$ ). STEM images were acquired on a FESEM Ultra plus (Zeiss) operating at $20 \mathrm{kV}$ from unstained samples. Non-contact mode AFM analysis was performed on a NX-10 instrument fitted with ACTA 10M cantilevers (Park systems). Cross-polarised microscopy was performed on an Olympus BX51 fitted with two rotary polarisers. Wide-angle X-ray scattering (WAXS) was measured on a Bruker D8 VENTURE PHOTON-III 14 k-geometry diffractometer fitted

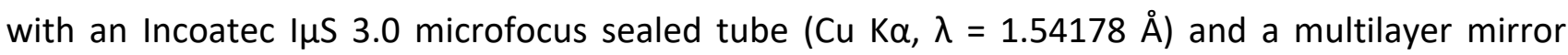
monochromator. Circular dichroism spectra were recorded on a Jasco J-1100 CD spectrometer from a $2 \mathrm{~mm}$ quartz cuvette. Fluorescence spectra were acquired on a Varian Cary Eclipse from a $1 \mathrm{~cm}$ quartz cuvette. Dynamic light scattering (DLS) data was acquired on a Zetasizer Nano ZSP (Malvern).

\section{Abbreviations}

AcCN: acetonitrile; DCM: dichloromethane; DIPEA: N,N-diisopropylethylamine; DMF: $N, N$ dimethylformamide; DMSO: dimethyl sulfoxide; FITC: fluorescein isothiocyanate; Fmoc: 9fluorenylmethyloxycarbonyl; $\quad$ HBTU: $\quad N, N, N^{\prime}, N^{\prime}$-tetramethyl-O-(1H-benzotriazol-1-yl)uranium hexafluorophosphate; PyAOP: (7-azabenzotriazol-1-yloxy)trispyrrolidinophosphonium hexafluorophosphate; TFA: trifluoroacetic acid, ThT: thioflavin-T, TIPS: triisopropylsilane, Trt: trityl. 


\section{Synthesis and purification of cyclic peptides}
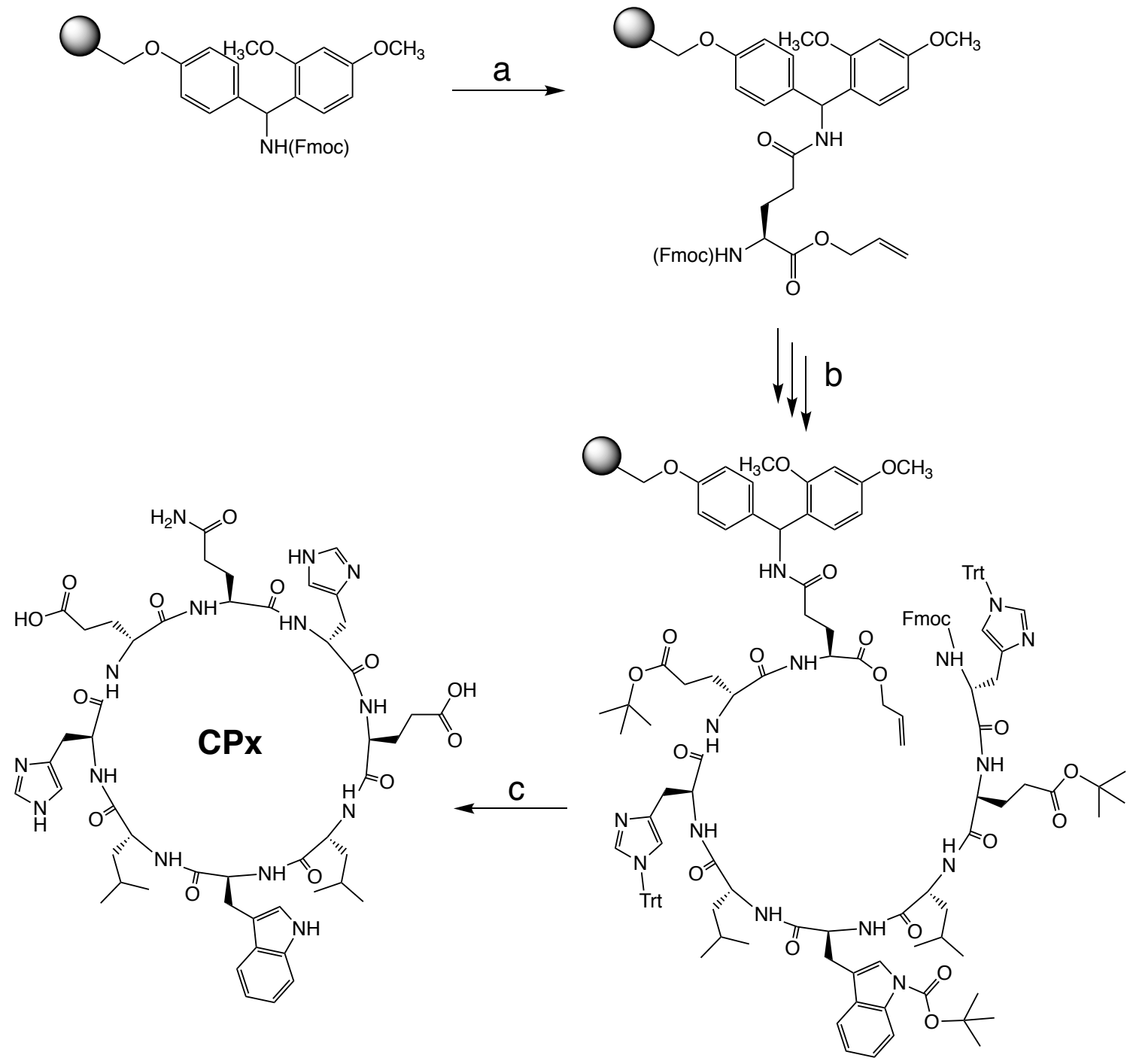

Scheme S1 a) Rink amide resin functionalisation: i) Piperidine 20\% v/v in DMF, 30 min; ii) Fmoc-LGlu-OAll, HBTU, DIPEA, DMF, 1h. b) Peptide elongation: i) Piperidine 20\% v/v in DMF, 15 min; ii) amino acid, HBTU, DIPEA, DMF, 30 min; Repeat 7 cycles with the corresponding amino acids. c) i) OAllyl removal: $\mathrm{Pd}(\mathrm{OAc})_{2}, \mathrm{PPh}_{3}$, phenylsilane, 4-methylmorpholine, $\mathrm{DCM}$, overnight; ii) Fmoc removal: Piperidine 20\% v/v in DMF, 30 min; iii) Peptide cyclisation: PyAOP, DIPEA, DMF, overnight; iv) Peptide cleavage from the resin: TFA, DCM, $\mathrm{H}_{2} \mathrm{O}, \mathrm{TIPS}, 2 \mathrm{~h}$. 


\section{Detailed synthetic protocol:}

Fmoc-Rink amide SPPS resin $(135.0 \mathrm{mg}, 0.1 \mathrm{mmol}$ ) was swollen in DMF for $30 \mathrm{~min}$ and the Fmoc group removed by treatment with piperidine $20 \% \mathrm{v} / \mathrm{v}$ in DMF $(2 \mathrm{~mL})$ for $30 \mathrm{~min}$. The resin was then washed and treated with Fmoc-L-Glu(OH)-OAll (163.6 mg, 0.4 mmol), HBTU (151.5 mg, $0.4 \mathrm{mmol})$ and DIPEA (105 $\mu \mathrm{L}, 0.6 \mathrm{mmol})$ in DMF $(2 \mathrm{~mL})$ for $1 \mathrm{~h}$. After this time, we followed cycles of Fmoc removal ( $2 \mathrm{~mL}$ of piperidine $20 \% \mathrm{v} / \mathrm{v}$ in DMF for $15 \mathrm{~min}$ ) and amino acid coupling $(0.4 \mathrm{mmol}$ of amino acid, $0.4 \mathrm{mmol}$ of HBTU, $0.6 \mathrm{mmol}$ of DIPEA in $2 \mathrm{~mL}$ of DMF for $30 \mathrm{~min}$ ) until all amino acids were coupled, leaving the $N$-terminal Fmoc group still on the peptide.

For OAllyl removal, the resin was thoroughly washed with DMF and DCM, and then reacted with 2 $\mathrm{mL}$ of a pre-mixed cocktail of $\mathrm{Pd}(\mathrm{OAc})_{2}(6.7 \mathrm{mg}, 0.03 \mathrm{mmol}), \mathrm{PPh}_{3}(39.3 \mathrm{mg}, 0.15 \mathrm{mmol})$, 4methylmorpholine $(110 \mu \mathrm{L}, 1.0 \mathrm{mmol})$ and phenylsilane $(123 \mu \mathrm{L}, 1.0 \mathrm{mmol})$ in dry DCM overnight. The resin was then filtered and washed with DCM, $10 \mathrm{~mL}$ of DIPEA $2 \% \mathrm{v} / \mathrm{v}$ in DMF, DMF, and then twice with $2 \mathrm{~mL}$ of $0.5 \% \mathrm{~m} / \mathrm{m}$ diethyldithiocarbamate in DMF for 30 min to remove all traces of $\mathrm{Pd}$.

For $\mathrm{N}$-terminal Fmoc removal, the resin was reacted with $2 \mathrm{~mL}$ of piperidine $20 \% \mathrm{v} / \mathrm{v}$ in DMF for 30 min and then washed with DMF.

The peptide was then cyclised by reacting the resin with PyAOP $(208.4 \mathrm{mg}, 0.4 \mathrm{mmol})$ and DIPEA (105 $\mu \mathrm{L}, 0.6 \mathrm{mmol}$ ) in $2 \mathrm{~mL}$ of DMF for 2 hours. This step was repeated twice more.

Once cyclised, the resin was washed with DMF and DCM, and the peptide was cleaved from the resin by treatment with $2 \mathrm{~mL}$ of TFA $(90 \% \mathrm{v} / \mathrm{v}), \mathrm{DCM}(5 \% \mathrm{v} / \mathrm{v}), \mathrm{H}_{2} \mathrm{O}(2.5 \% \mathrm{v} / \mathrm{v})$ and TIPS $(2.5 \% \mathrm{v} / \mathrm{v})$ for $2 \mathrm{~h}$. After this time, the acidic solution was filtered and concentrated under a flow of nitrogen, to be then precipitated into $45 \mathrm{~mL}$ of chilled diethyl ether. The suspension thus obtained was centrifuged ( $3 \mathrm{krcf}, 10 \mathrm{~min}$ ) and the pellet dissolved in a 1:1 mixture of $\mathrm{H}_{2} \mathrm{O}: \mathrm{AcCN}$ and purified by preparative reverse-phase $\mathrm{HPLC}\left(\mathrm{A}=\mathrm{H}_{2} \mathrm{O}+0.1 \% \mathrm{v} / \mathrm{v}\right.$ TFA; $B=\mathrm{AcCN}+0.1 \% \mathrm{v} / \mathrm{v}$ TFA; $\left.15 \mathrm{~mL} \cdot \mathrm{min}^{-1}\right): 0$ $\min (0 \% \mathrm{~B}) \rightarrow 5 \min (0 \% \mathrm{~B}) \rightarrow 30 \min (75 \% \mathrm{~B}) \rightarrow 35 \min (95 \% \mathrm{~B}) \rightarrow 40 \min (95 \% \mathrm{~B}) ; R_{t}=19.9 \min$. Peptide fractions were concentrated in vacuo to remove TFA and $\mathrm{AcCN}$, and the remaining aqueous solution was freeze dried.

A white powder was thus obtained: CPx (30 mg; $28 \%$ yield), CPxAla (15 mg; 15\% yield), CPx-Glu (37 $\mathrm{mg} ; 35 \%$ yield) and CPx-His (22 mg; 21\% yield). 


\section{CPx characterisation}

5.1. ${ }^{1} \mathrm{H}-\mathrm{NMR}\left(300 \mathrm{MHz}\right.$, DMSO- $\left.\boldsymbol{d}_{6}\right) \delta=0.64-1.31(\mathrm{~m}, 18 \mathrm{H}$, Leu $i-\mathrm{Bu} \times 2), 1.55-2.12\left(\mathrm{~m}, 12 \mathrm{H}, \mathrm{Glu}-\mathrm{C}_{2}{ }^{-}\right.$ $\left.\mathrm{x} 2+\mathrm{Gln}-\mathrm{C}_{2}-\right), 2.80-3.11\left(\mathrm{~m}, 6 \mathrm{H}, \mathrm{His}-\underline{\mathrm{C}}_{2}-\mathrm{x} 2+\operatorname{Trp}-\underline{\mathrm{C}}_{2}-\right), 4.27-4.49(\mathrm{~m}, 5 \mathrm{H}, \mathrm{H \alpha}), 4.62-4.85(\mathrm{~m}, 3 \mathrm{H}$, $\mathrm{H \alpha}), 6.76\left(\mathrm{~s}, 1 \mathrm{H}, \mathrm{Gln}-\mathrm{CONH}_{2}\right), 6.93(\mathrm{t}, J=7.3 \mathrm{~Hz}, 1 \mathrm{H}, \operatorname{Trp}), 7.02$ (t, $\left.J=7.3 \mathrm{~Hz}, 1 \mathrm{H}, \operatorname{Trp}\right), 7.11$ (d, $J=2.4$ Hz, 1H, Trp), 7.22 (s, 1H, Gln-CONH 2 ), 7.28 (d, J = 8.1 Hz, 1H, Trp), 7.33 (d, J = $13.5 \mathrm{~Hz}, 2 \mathrm{H}, \mathrm{His} \times 2$ ), $7.68(\mathrm{~d}, J=7.8 \mathrm{~Hz}, 1 \mathrm{H}, \operatorname{Trp}), 8.04(\mathrm{~d}, J=8.7 \mathrm{~Hz}, 1 \mathrm{H}, \mathrm{CONH}), 8.10(\mathrm{~d}, J=8.3 \mathrm{~Hz}, 1 \mathrm{H}, \mathrm{CONH}), 8.17(\mathrm{~d}, J=$ $8.2 \mathrm{~Hz}, 1 \mathrm{H}, \mathrm{CONH}), 8.26$ (d, J = 7.9 Hz, 1H, CONH), 8.32 (d, J = 8.3 Hz, 1H, CONH), 8.38 (d, J= $8.3 \mathrm{~Hz}$, $1 \mathrm{H}, \mathrm{CONH}), 8.40(\mathrm{~d}, J=8.2 \mathrm{~Hz}, 1 \mathrm{H}, \mathrm{CONH}), 8.46(\mathrm{~d}, J=8.7 \mathrm{~Hz}, 1 \mathrm{H}, \mathrm{CONH}), 8.96(\mathrm{dd}, J=11.9,1.3 \mathrm{~Hz}$, $2 \mathrm{H}, \mathrm{His} \times 2), 10.79(\mathrm{~d}, J=2.2 \mathrm{~Hz}, 1 \mathrm{H}, \mathrm{Trp}-\mathrm{NH}) \mathrm{ppm}$.

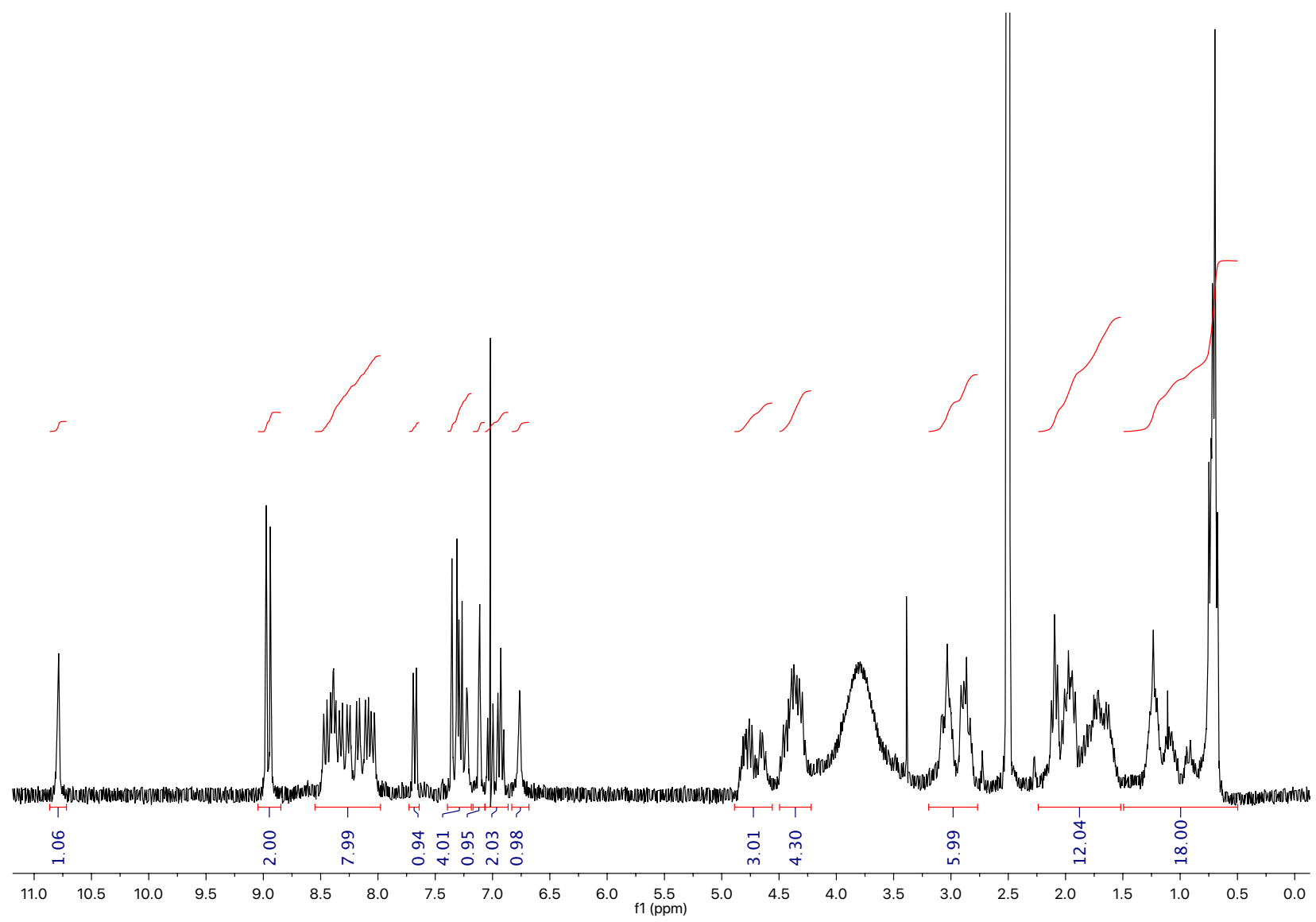

Figure $\mathbf{S 1}{ }^{1} \mathrm{H}-\mathrm{NMR}$ spectrum (300 MHz, DMSO- $d_{6}$ ) of $\mathbf{C P x}$. 
5.2. UHPLC-MS (C18-ESI, +eV) $A=\mathrm{H}_{2} \mathrm{O}+0.1 \% \mathrm{v} / \mathrm{v}$ TFA; $B=\mathrm{AcCN}+0.1 \% \mathrm{v} / \mathrm{v}$ TFA; $0.35 \mathrm{~mL} \cdot \mathrm{min}^{-1}: 0$ $\min (0 \% \mathrm{~B}) \rightarrow 2 \min (0 \% \mathrm{~B}) \rightarrow 21 \min (75 \% \mathrm{~B}) \rightarrow 22 \min (95 \% \mathrm{~B}) ; R_{t}=12.5 \mathrm{~min} . \mathrm{m} / \mathrm{z}=1,073.4$ $\left([\mathrm{M}+\mathrm{H}]^{+}\right), 537.3\left([\mathrm{M}+2 \mathrm{H}]^{2+}\right)$.
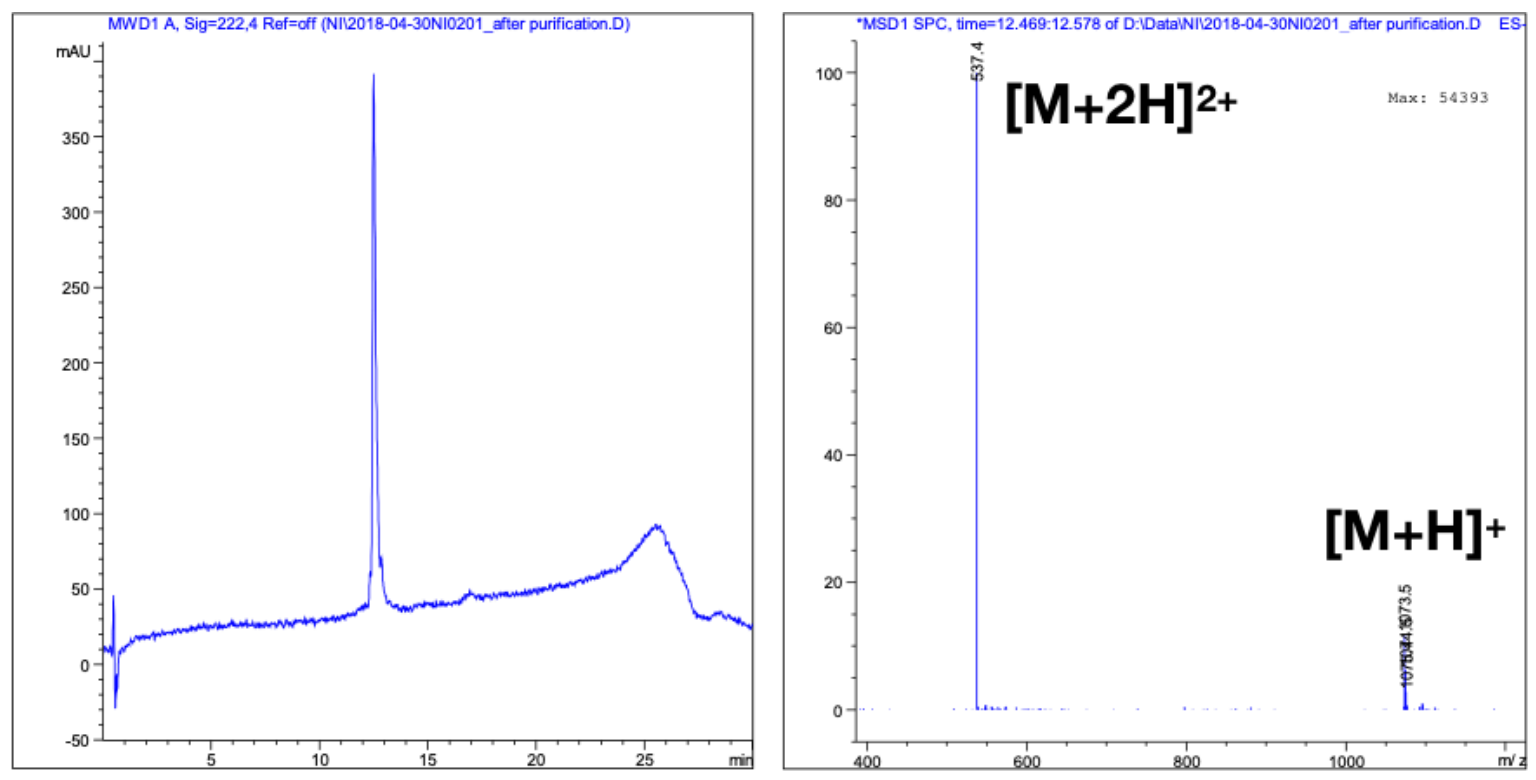

Figure S2 Reverse-phase UHPLC (left) and mass spectrum of the peak in the chromatogram (right) of CPx.

5.3. HR-MS (ESI, +eV) m/z = 1073.5163 (calculated for $[M+H]^{+}$) 1073.5162 (found).

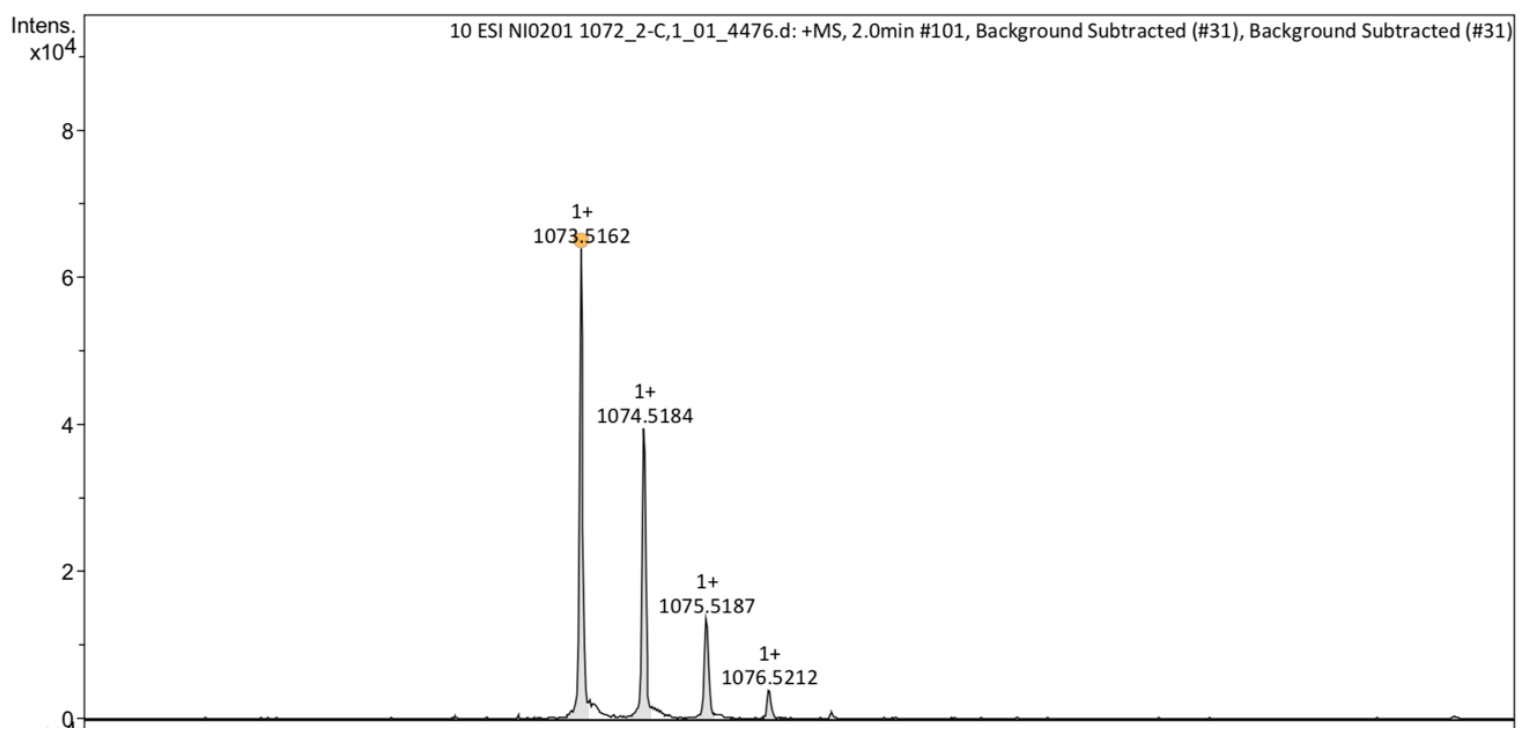

Figure S3 High resolution mass spectrometry (HR-MS) analysis of CPx. 


\section{CPxAla characterisation}

6.1. ${ }^{1} \mathrm{H}-\mathrm{NMR}\left(300 \mathrm{MHz}, \mathrm{DMSO}-\boldsymbol{d}_{6}\right) \delta=0.94(\mathrm{t}, J=6.6 \mathrm{~Hz}, 6 \mathrm{H}$, Ala $x 2), 1.56-2.12\left(\mathrm{~m}, 12 \mathrm{H}\right.$, Glu $\left.-\underline{\mathrm{C}}_{2}-\mathrm{x} 2+\mathrm{Gln}-\mathrm{C}_{2}-\right), 2.80-3.09(\mathrm{~m}$, $6 \mathrm{H}$, His $\left.-\underline{\mathrm{C}}_{2}-\mathrm{x} 2+\operatorname{Trp}-\underline{\mathrm{C}}_{2}-\right), 4.25-4.45(\mathrm{~m}, 5 \mathrm{H}, \mathrm{H \alpha}), 4.52-4.60(\mathrm{~m}$, $1 \mathrm{H}, \mathrm{H \alpha}), 4.69-4.79(\mathrm{~m}, 2 \mathrm{H}, \mathrm{H \alpha}), 6.77\left(\mathrm{~s}, 1 \mathrm{H}, \mathrm{Gln}-\mathrm{CONH}_{2}\right), 6.94(\mathrm{t}, \mathrm{J}$ $=7.4 \mathrm{~Hz}, 1 \mathrm{H}, \operatorname{Trp}), 7.03(\mathrm{t}, J=7.3 \mathrm{~Hz}, 1 \mathrm{H}, \operatorname{Trp}), 7.12(\mathrm{~d}, J=2.3 \mathrm{~Hz}$, 1H, Trp), 7.22 (s, 1H, Gln-CONH 2 ), 7.29 (d, $J=7.7 \mathrm{~Hz}, 1 \mathrm{H}, \operatorname{Trp})$, $7.32(\mathrm{~d}, J=12.7 \mathrm{~Hz}, 2 \mathrm{H}$, His x2), $7.62(\mathrm{~d}, J=7.7 \mathrm{~Hz}, 1 \mathrm{H}, \operatorname{Trp}), 8.11$ (d, $J=8.3 \mathrm{~Hz}, 2 \mathrm{H}, \mathrm{CONH}), 8.17(\mathrm{~d}, J=8.3 \mathrm{~Hz}, 1 \mathrm{H}, \mathrm{CONH}), 8.24-$

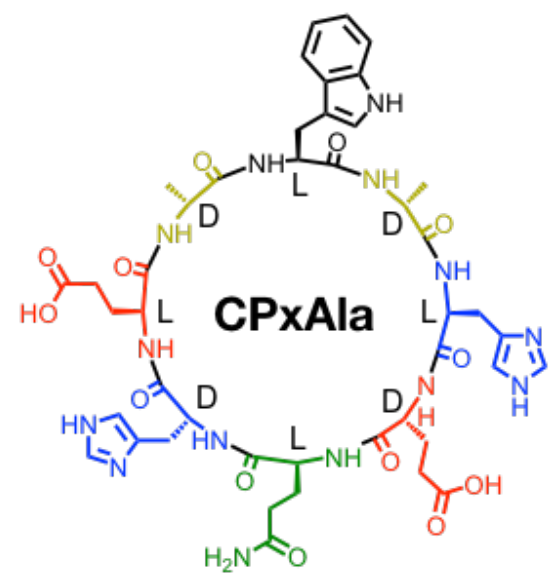
$8.31(\mathrm{~m}, 4 \mathrm{H}, \mathrm{CONH}), 8.43(\mathrm{~d}, J=8.4 \mathrm{~Hz}, 1 \mathrm{H}, \mathrm{CONH}), 8.95(\mathrm{~d}, J=5.4 \mathrm{~Hz}, 2 \mathrm{H}, \mathrm{His} \times 2), 10.78(\mathrm{~s}, 1 \mathrm{H}, \operatorname{Trp}-$ $\mathrm{NH}) \mathrm{ppm}$.

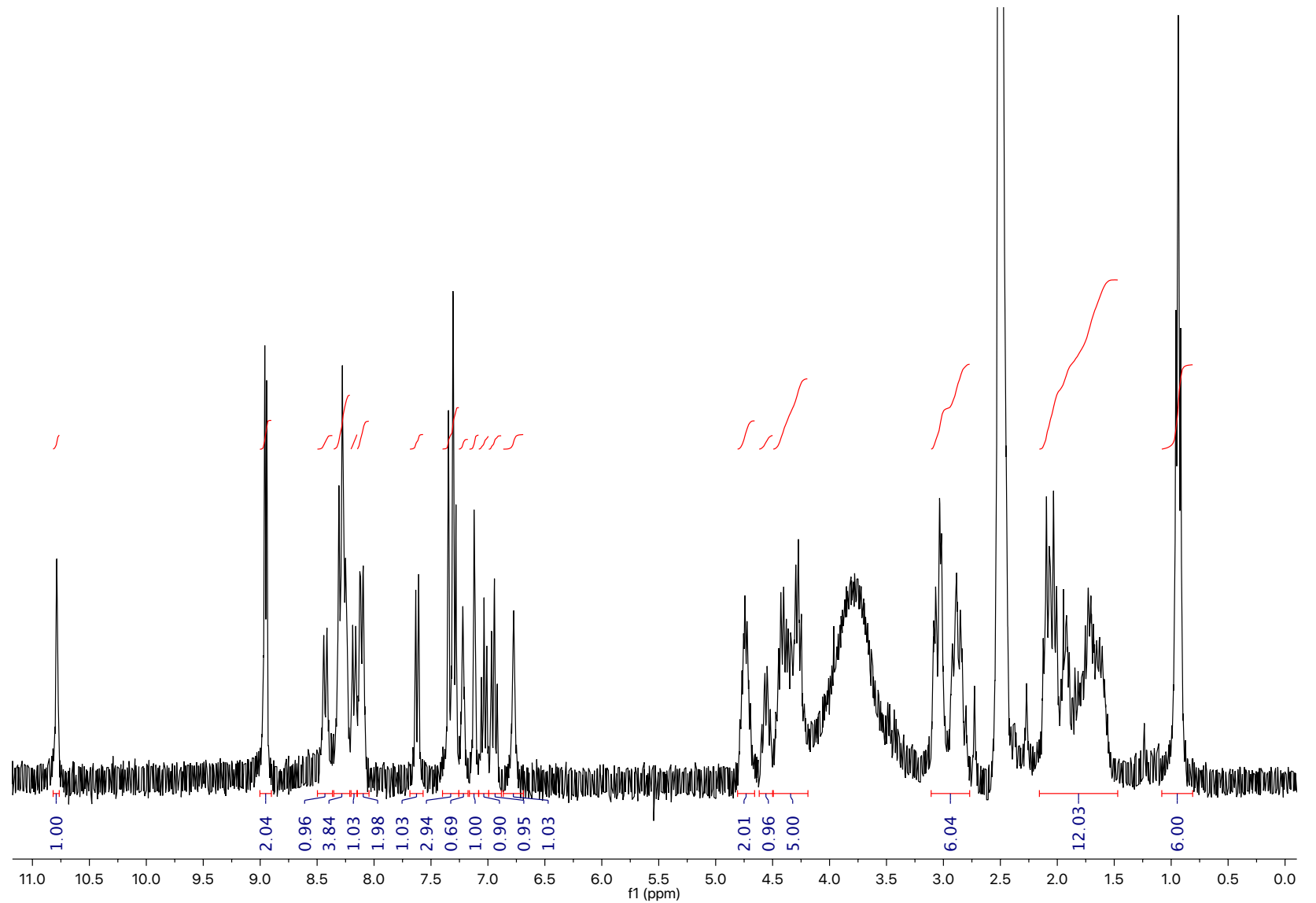

Figure S4 ${ }^{1} \mathrm{H}-\mathrm{NMR}$ spectrum $\left(300 \mathrm{MHz}\right.$, DMSO- $\left.d_{6}\right)$ of CPxAla. 
6.2. UHPLC-MS (C18-ESI, + eV) $A=\mathrm{H}_{2} \mathrm{O}+0.1 \% \mathrm{v} / \mathrm{v}$ TFA; $B=A c C N+0.1 \% \mathrm{v} / \mathrm{v}$ TFA; $0.35 \mathrm{~mL} \cdot \mathrm{min}^{-1}: 0$ $\min (0 \% \mathrm{~B}) \rightarrow 2 \min (0 \% \mathrm{~B}) \rightarrow 21 \mathrm{~min}(75 \% \mathrm{~B}) \rightarrow 22 \min (95 \% \mathrm{~B}) ; R_{t}=9.9 \min . \mathrm{m} / \mathrm{z}=989.4\left([\mathrm{M}+\mathrm{H}]^{+}\right)$, $495.4\left([\mathrm{M}+2 \mathrm{H}]^{2+}\right)$.
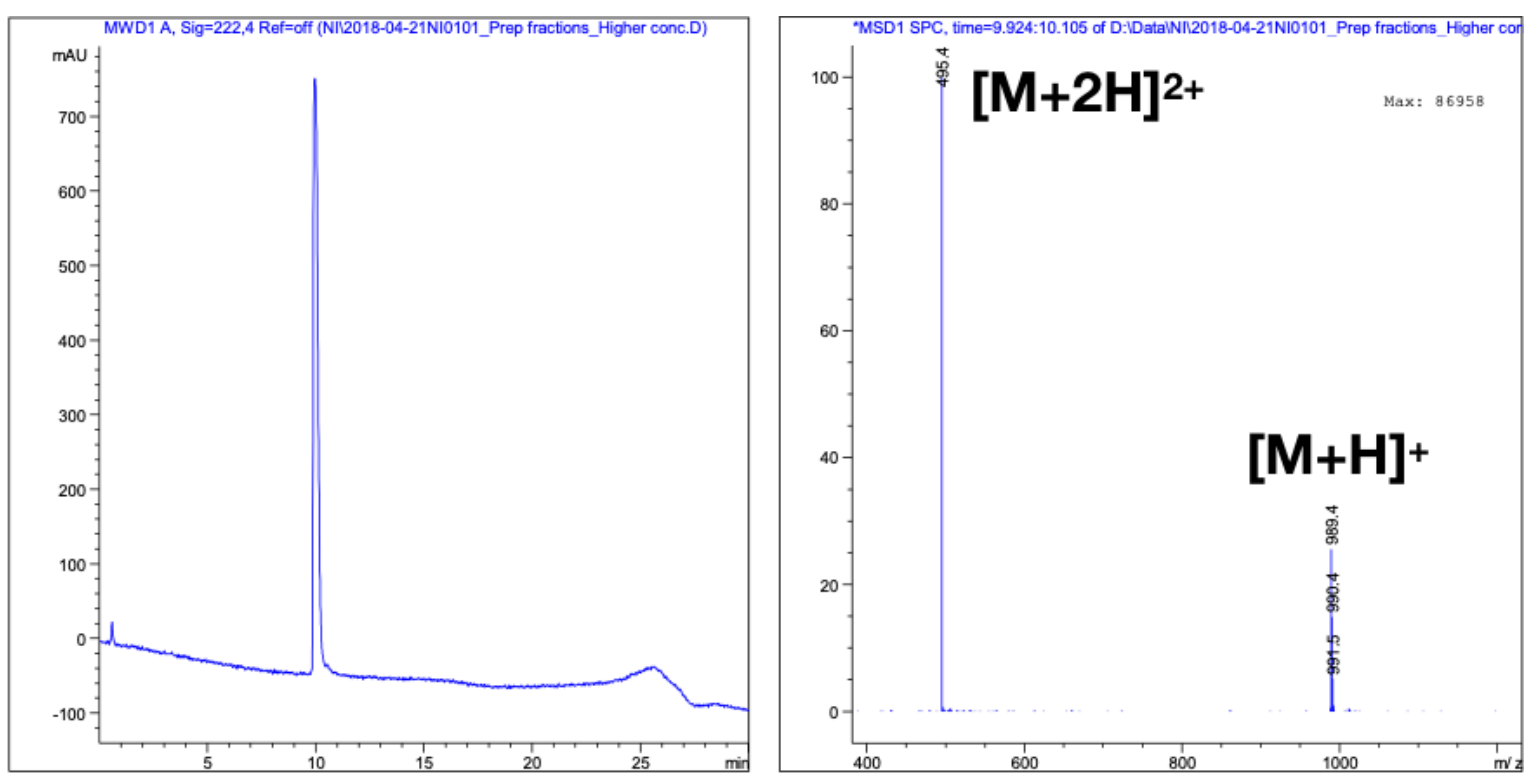

Figure S5 Reverse-phase UHPLC (left) and mass spectrum of the peak in the chromatogram (right) of CPxAla.

6.3. HR-MS (ESI, $+e V) m / z=989.4224$ (calculated for $\left.[M+H]^{+}\right) 989.4228$ (found).

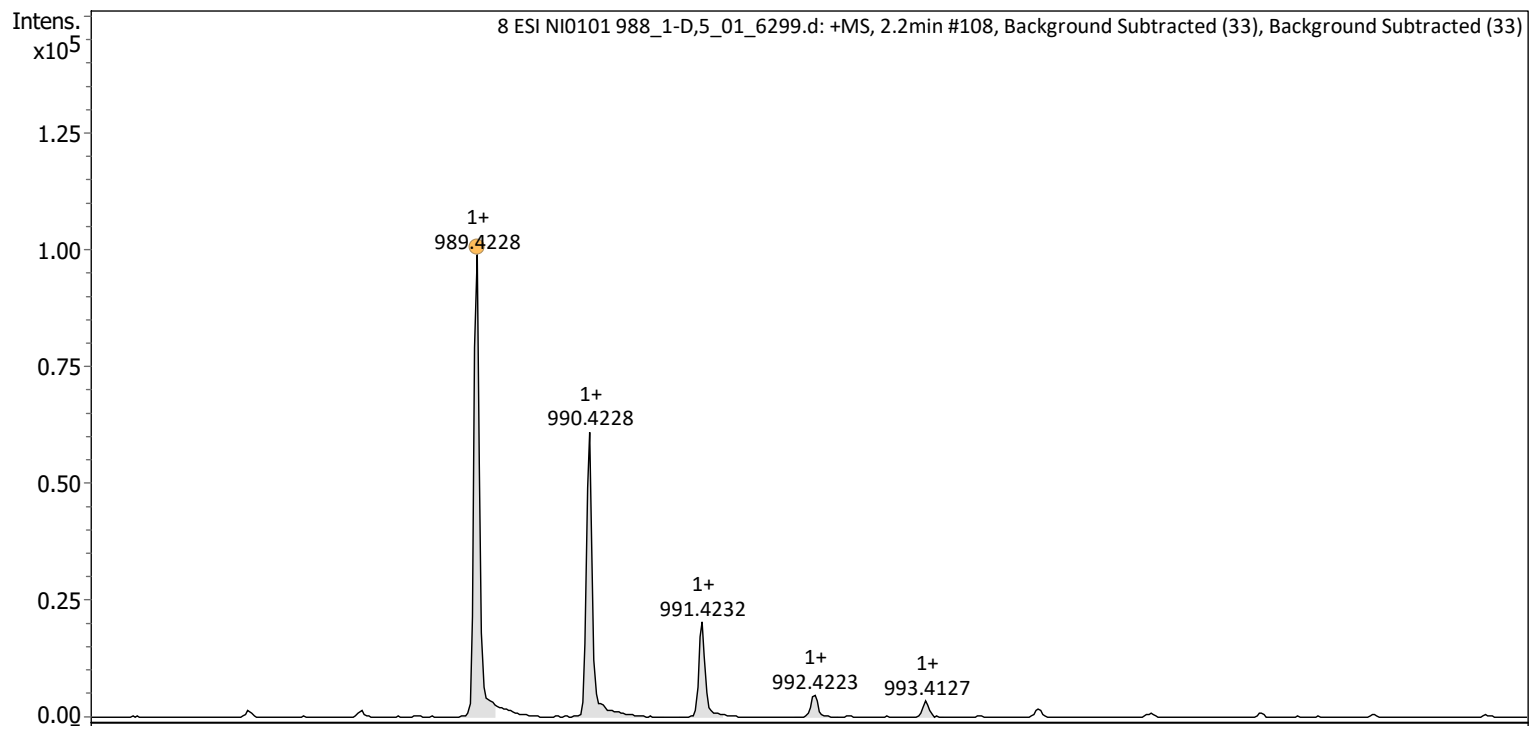

Figure S6 High resolution mass spectrometry (HR-MS) analysis of CPxAla. 


\section{CPx-Glu characterisation}

7.1. ${ }^{1} \mathrm{H}-\mathrm{NMR}\left(500 \mathrm{MHz}\right.$, DMSO- $\left.d_{6}\right) \delta=0.69-1.26(\mathrm{~m}, 18 \mathrm{H}$, Leu $i-$ $\mathrm{Bu} \times 2), 1.58-2.11\left(\mathrm{~m}, 12 \mathrm{H}, \mathrm{Gln}-\mathrm{C}_{2}-\mathrm{x} 3\right), 2.84-3.11(\mathrm{~m}, 6 \mathrm{H}$, His $\left.\mathrm{C}_{2}{ }^{-} \mathrm{x} 2+\operatorname{Trp}-\mathrm{C}_{2}-\right), 4.20-4.44(\mathrm{~m}, 5 \mathrm{H}, \mathrm{H \alpha}), 4.62-4.81(\mathrm{~m}, 3 \mathrm{H}$, $\mathrm{H \alpha}), 6.74\left(\mathrm{~s}, 1 \mathrm{H}, \mathrm{Gln}-\mathrm{CONH}_{2}\right), 6.80$ (s, 2H, Gln-CONH$\left.{ }_{2} \times 2\right), 6.93$ (t, $J=7.7 \mathrm{~Hz}, 1 \mathrm{H}, \operatorname{Trp}), 7.01(\mathrm{t}, J=8.0 \mathrm{~Hz}, 1 \mathrm{H}, \operatorname{Trp}), 7.11(\mathrm{~d}, J=2.7 \mathrm{~Hz}$, $1 \mathrm{H}, \operatorname{Trp}), 7.22$ (s, 2H, Gln-CONH$\left.{ }_{2} \times 2\right), 7.24$ (s, 1H, Gln-CONH${ }_{2}$ ), $7.28(\mathrm{~d}, J=8.0 \mathrm{~Hz}, 1 \mathrm{H}, \operatorname{Trp}), 7.32$ (d, J = $16.8 \mathrm{~Hz}, 2 \mathrm{H}$, His x2), 7.66 (d, $J=7.9 \mathrm{~Hz}, 1 \mathrm{H}, \operatorname{Trp}), 8.01$ (d, $J=8.5 \mathrm{~Hz}, 1 \mathrm{H}, \mathrm{CONH}$ ), 8.09 (d, $J=$

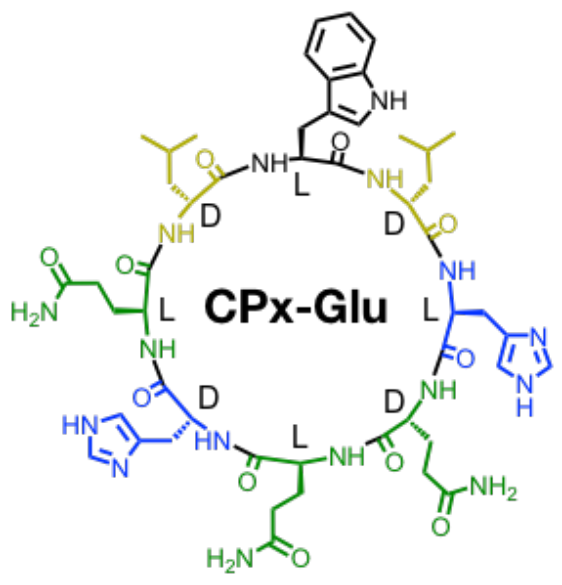
$8.4 \mathrm{~Hz}, 1 \mathrm{H}, \mathrm{CONH}), 8.15$ (d, $J=8.3 \mathrm{~Hz}, 1 \mathrm{H}, \mathrm{CONH}), 8.28$ (d, $J=8.6 \mathrm{~Hz}, 1 \mathrm{H}, \mathrm{CONH}), 8.29$ (d, J= $8.3 \mathrm{~Hz}$, $1 \mathrm{H}, \mathrm{CONH}), 8.33(\mathrm{~d}, J=8.5 \mathrm{~Hz}, 1 \mathrm{H}, \mathrm{CONH}), 8.37$ (d, $J=8.0 \mathrm{~Hz}, 1 \mathrm{H}, \mathrm{CONH}), 8.47$ (d, J=8.7 Hz, $1 \mathrm{H}$, CONH), 8.95 (dd, $J=18.5,1.3 \mathrm{~Hz}, 2 \mathrm{H}$, His x2), 10.79 (s, 1H, Trp-NH) ppm.

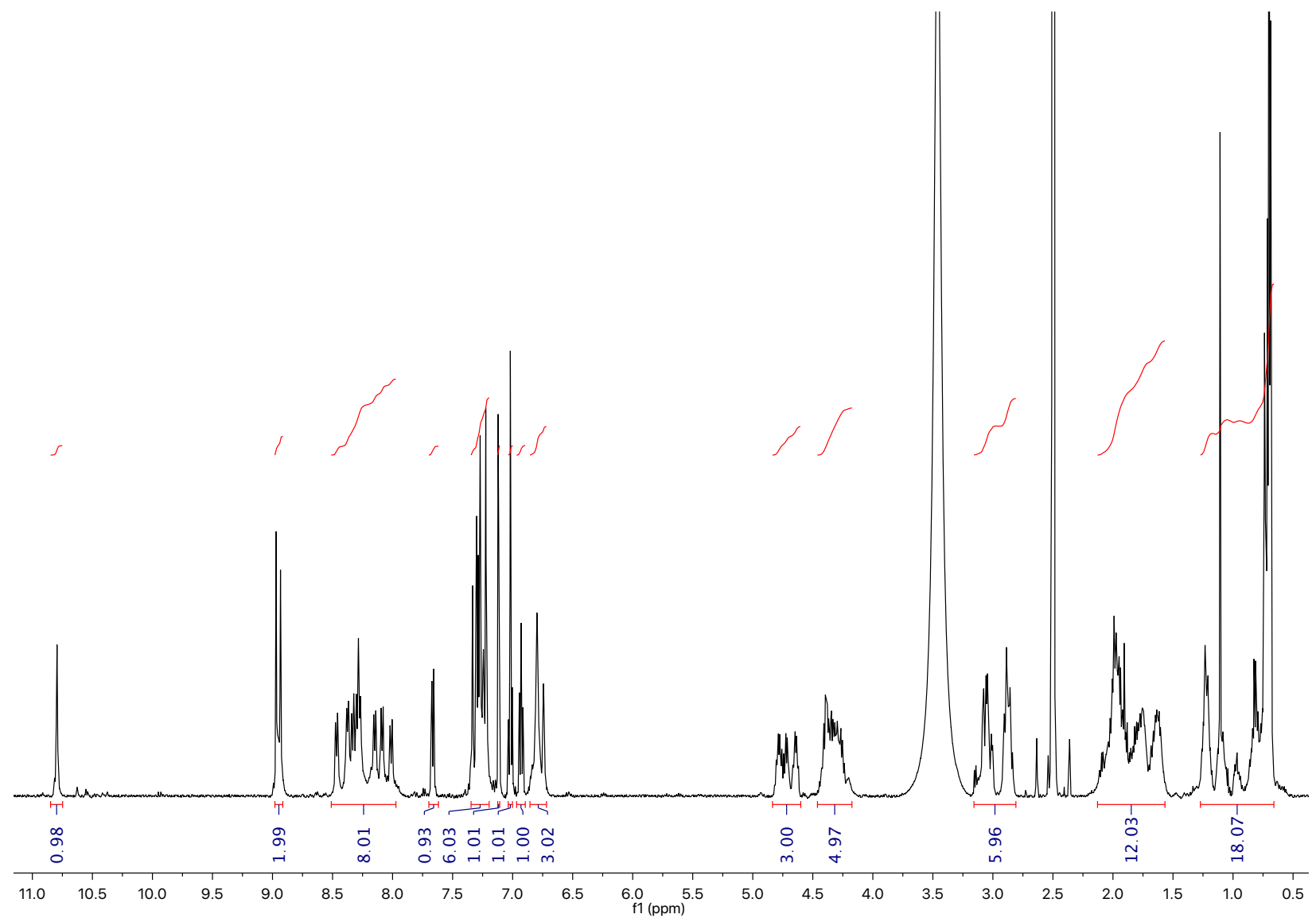

Figure $\mathbf{S 7}{ }^{1} \mathrm{H}-\mathrm{NMR}$ spectrum $\left(500 \mathrm{MHz}\right.$, DMSO- $\left.d_{6}\right)$ of $\mathrm{CPx}$-Glu. 
7.2. UHPLC-MS (C18-ESI, +eV) $A=\mathrm{H}_{2} \mathrm{O}+0.1 \% \mathrm{v} / \mathrm{v}$ TFA; $B=\mathrm{AcCN}+0.1 \% \mathrm{v} / \mathrm{v}$ TFA; $0.35 \mathrm{~mL} \cdot \mathrm{min}^{-1}: 0$ $\min (0 \% \mathrm{~B}) \rightarrow 2 \min (0 \% \mathrm{~B}) \rightarrow 21 \mathrm{~min}(75 \% \mathrm{~B}) \rightarrow 22 \mathrm{~min}(95 \% \mathrm{~B}) ; R_{t}=11.9 \mathrm{~min} . \mathrm{m} / \mathrm{z}=1071.6$ $\left([\mathrm{M}+\mathrm{H}]^{+}\right), 536.4\left([\mathrm{M}+2 \mathrm{H}]^{2+}\right)$.
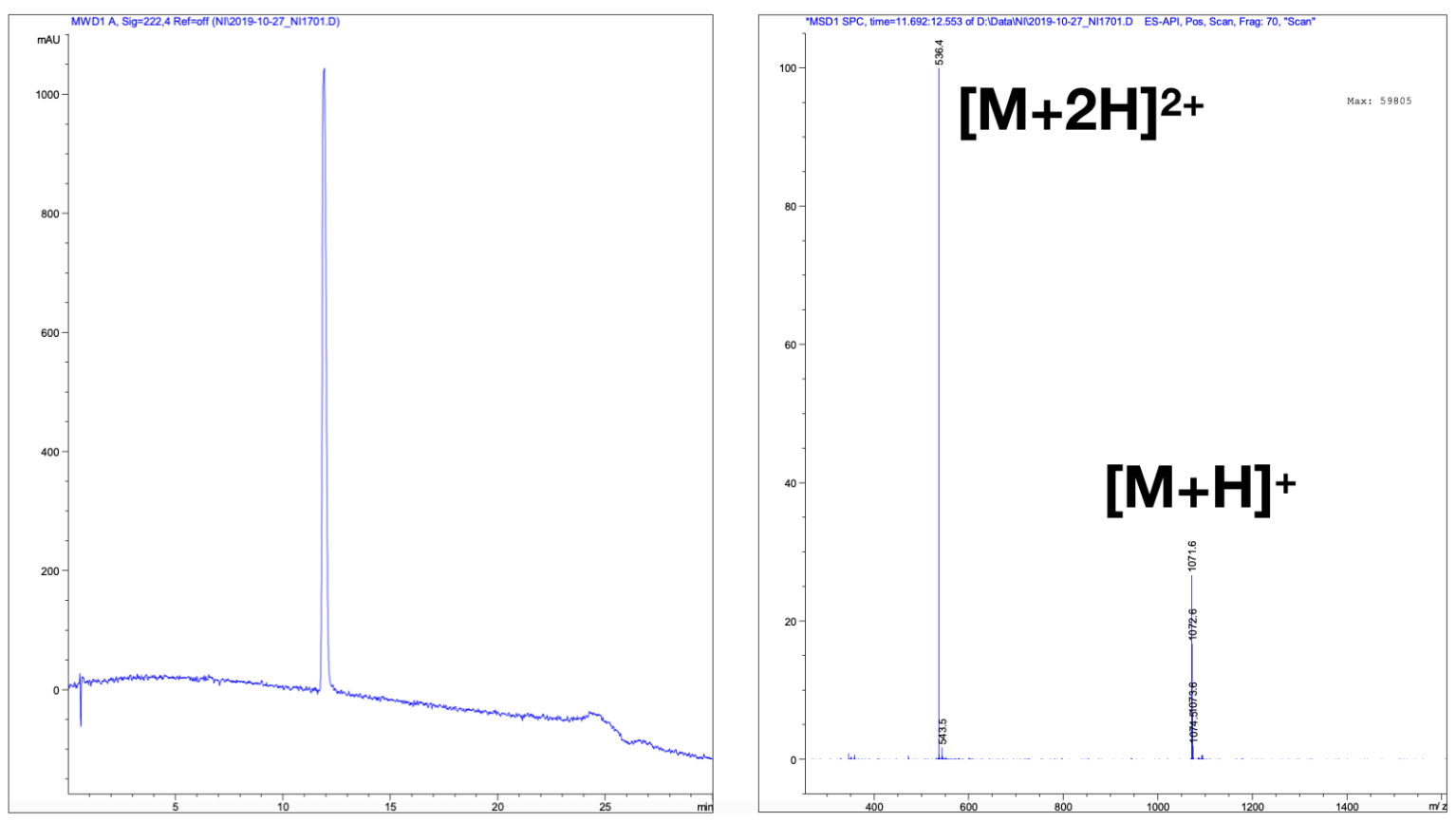

Figure $\mathbf{8} 8$ Reverse-phase UHPLC (left) and mass spectrum of the peak in the chromatogram (right) of CPx-Glu.

6.3. HR-MS $(E S I,+e V) m / z=1071.5483$ (calculated for $[M+H]^{+}$) 1071.5481 (found).

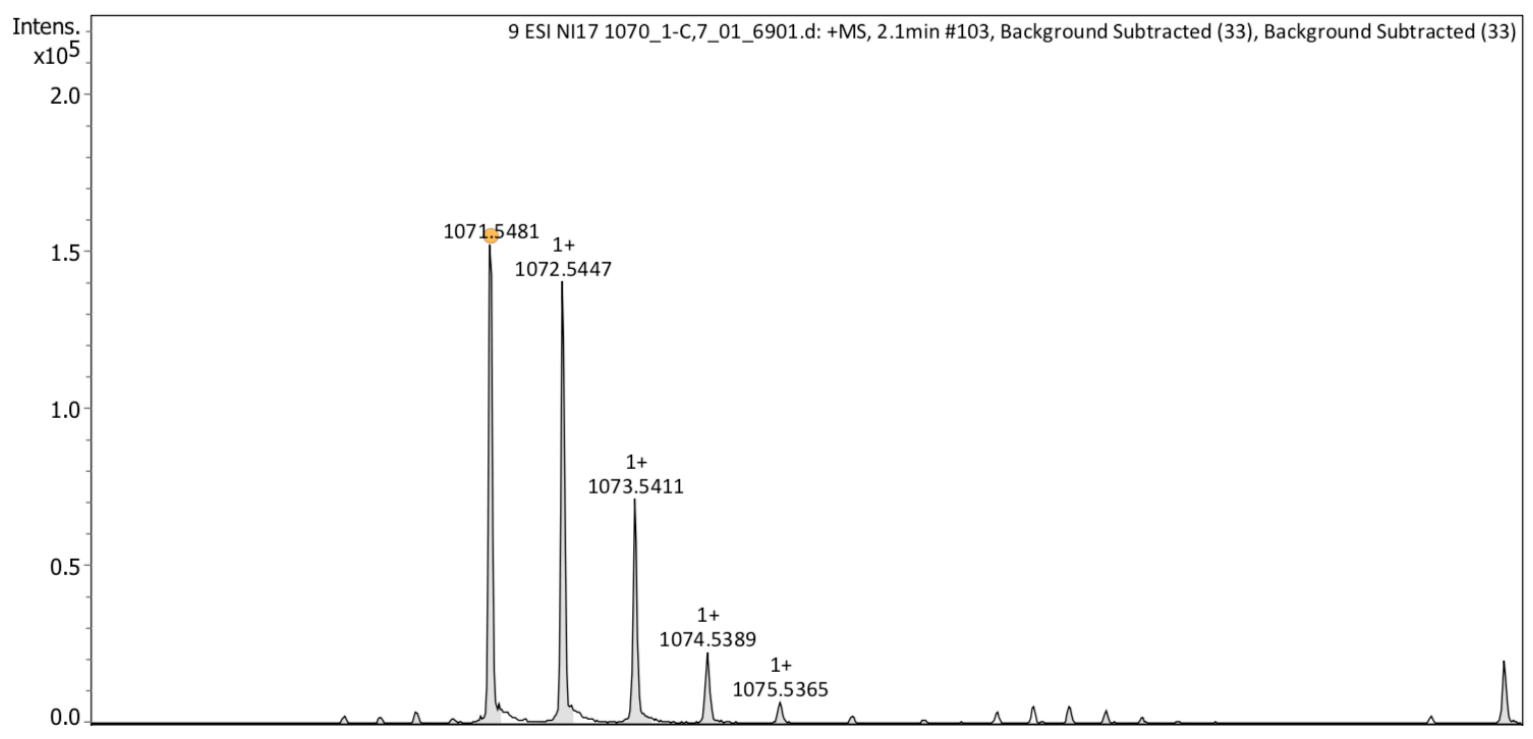

Figure S9 High resolution mass spectrometry (HR-MS) analysis of CPx-Glu. 


\section{8. $\mathrm{CPx}$-His characterisation}

8.1. ${ }^{1} \mathrm{H}-\mathrm{NMR}\left(500 \mathrm{MHz}\right.$, DMSO- $d_{6}:$ TFA [8:1]) $\delta=0.69-0.88(\mathrm{~m}$, $12 \mathrm{H}$, Leu $\left.-\mathrm{CH}_{3} \times 4\right)$, $1.33-1.56\left(\mathrm{~m}, 6 \mathrm{H}\right.$, Leu $\left.-\mathrm{CH}_{2} \mathrm{CH}-\mathrm{x} 2\right)$, 1.73-2.24 $\left(\mathrm{m}, 2 \mathrm{H}, \mathrm{Gln}+\mathrm{Glu}-\left(\mathrm{CH}_{2}\right)_{2^{-}} \mathrm{x} 5\right), 2.90-3.16\left(\mathrm{~m}, 2 \mathrm{H}, \operatorname{Trp}-\mathrm{CH}_{2}{ }^{-}\right)$,

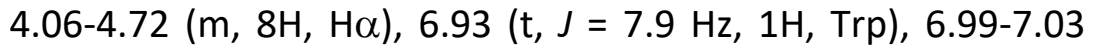
(m, 1H, Trp), 7.13 (d, J=15.6 Hz, 1H, Trp), 7.28 (d, $J=8.5 \mathrm{~Hz}$, $1 \mathrm{H}, \operatorname{Trp}), 7.66(\mathrm{t}, J=9.5 \mathrm{~Hz}, 1 \mathrm{H}, \operatorname{Trp}), 7.91-8.44(\mathrm{~m}, 8 \mathrm{H}, \mathrm{CONH})$, $10.74(\mathrm{~s}, 1 \mathrm{H}, \mathrm{Trp}-\mathrm{NH}) \mathrm{ppm}$.
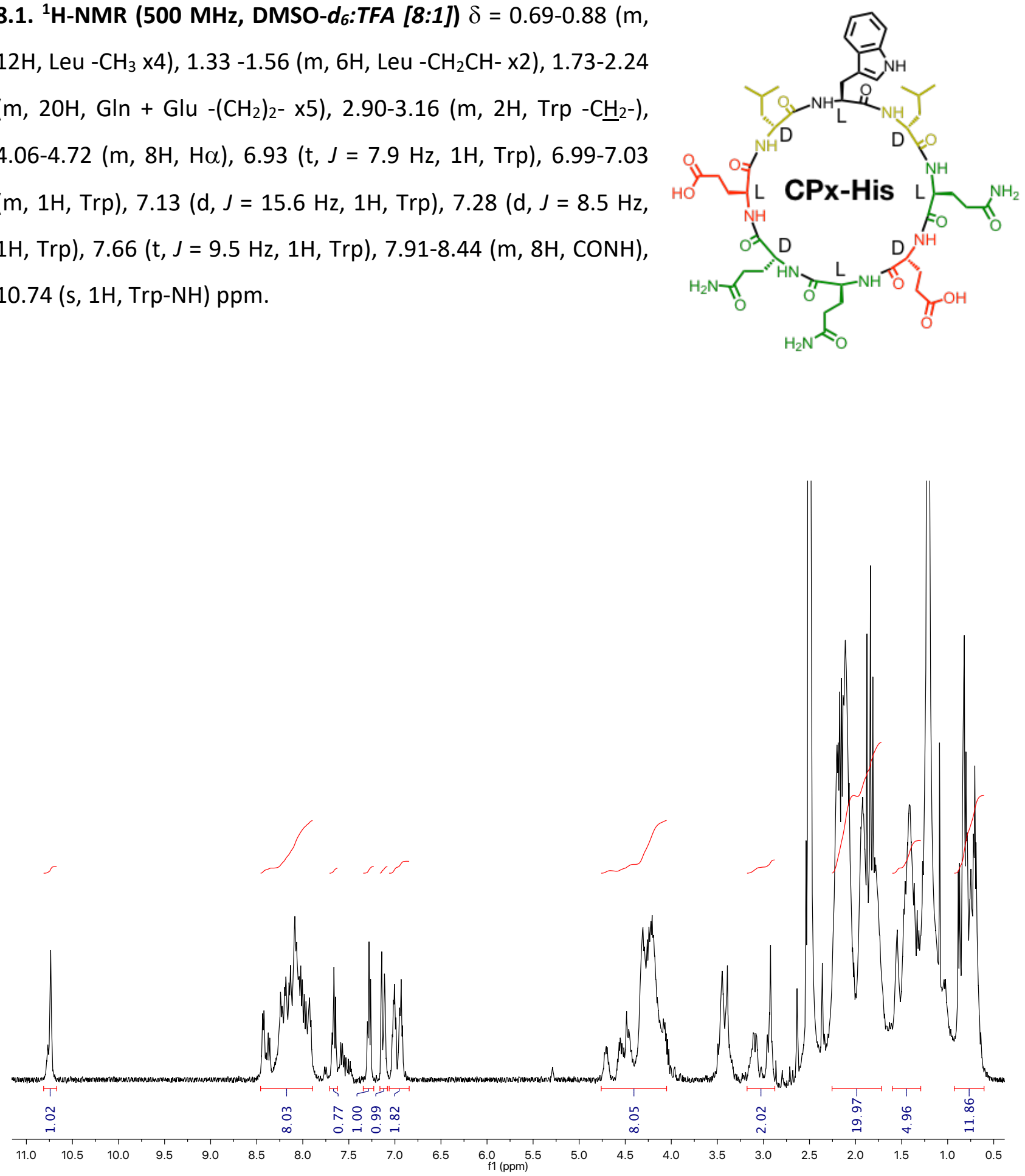

Figure $\mathbf{S} 10^{1} \mathrm{H}-\mathrm{NMR}$ spectrum (500 MHz, DMSO- $d_{6}: T F A$ [8:1]) of CPx-His. 
8.2. UHPLC-MS (C18-ESI, $+\mathrm{eV}) \mathrm{A}=\mathrm{H}_{2} \mathrm{O}+0.1 \% \mathrm{v} / \mathrm{v}$ TFA; $\mathrm{B}=\mathrm{ACCN}+0.1 \% \mathrm{v} / \mathrm{v}$ TFA; $0.35 \mathrm{~mL} \cdot \mathrm{min}^{-1}: 0$ $\min (0 \% \mathrm{~B}) \rightarrow 2 \min (0 \% \mathrm{~B}) \rightarrow 21 \mathrm{~min}(75 \% \mathrm{~B}) \rightarrow 22 \min (95 \% \mathrm{~B}) ; R_{t}=12.9 \mathrm{~min} . \mathrm{m} / \mathrm{z}=1055.6$ $\left([\mathrm{M}+\mathrm{H}]^{+}\right), 528.4\left([\mathrm{M}+2 \mathrm{H}]^{2+}\right)$.
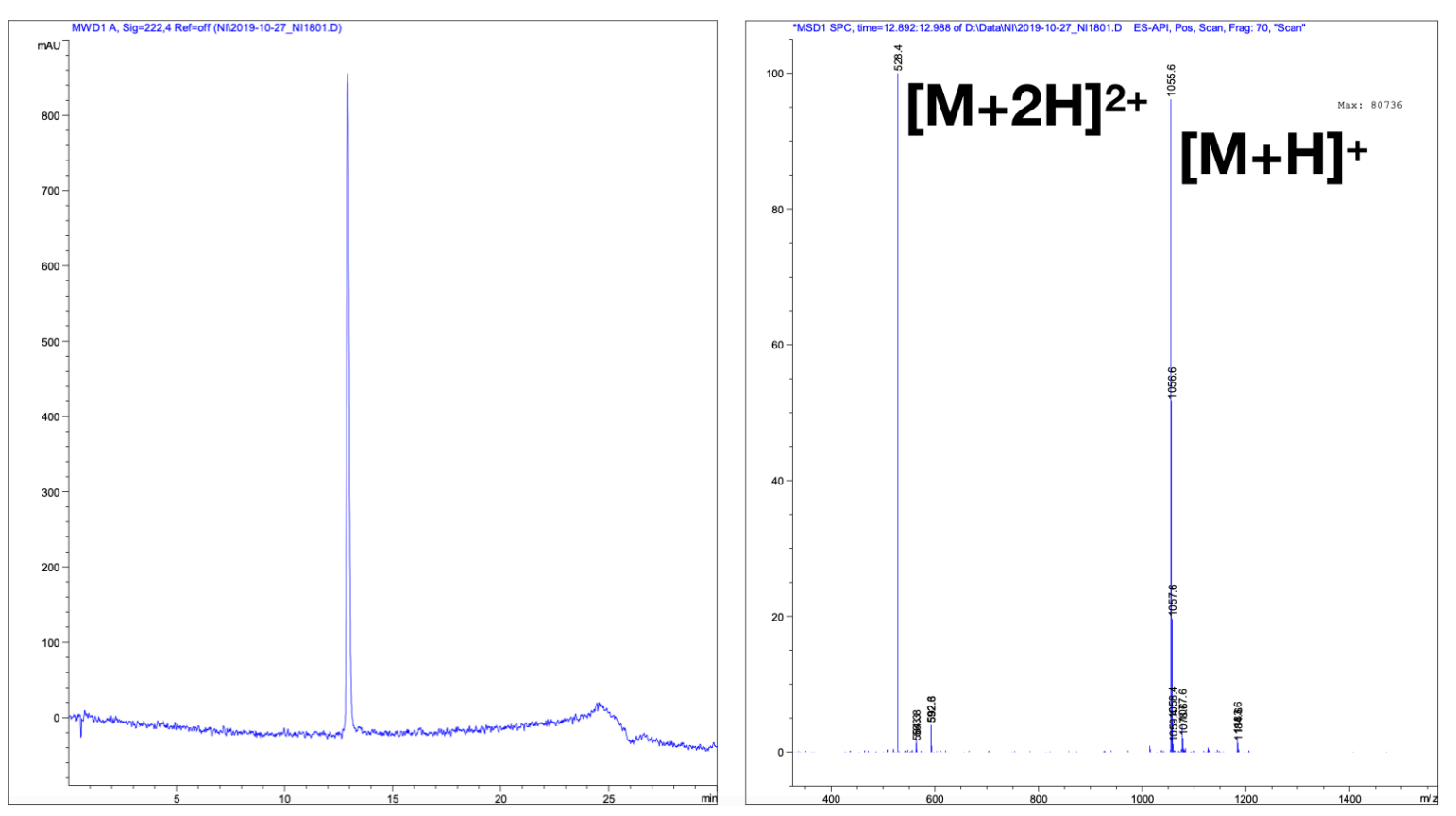

Figure S11 Reverse-phase UHPLC (left) and mass spectrum of the peak in the chromatogram (right) of CPx-His.

6.3. HR-MS (ESI, +eV) m/z = 1055.5156 (calculated for $\left.[M+H]^{+}\right) 1055.5153$ (found).

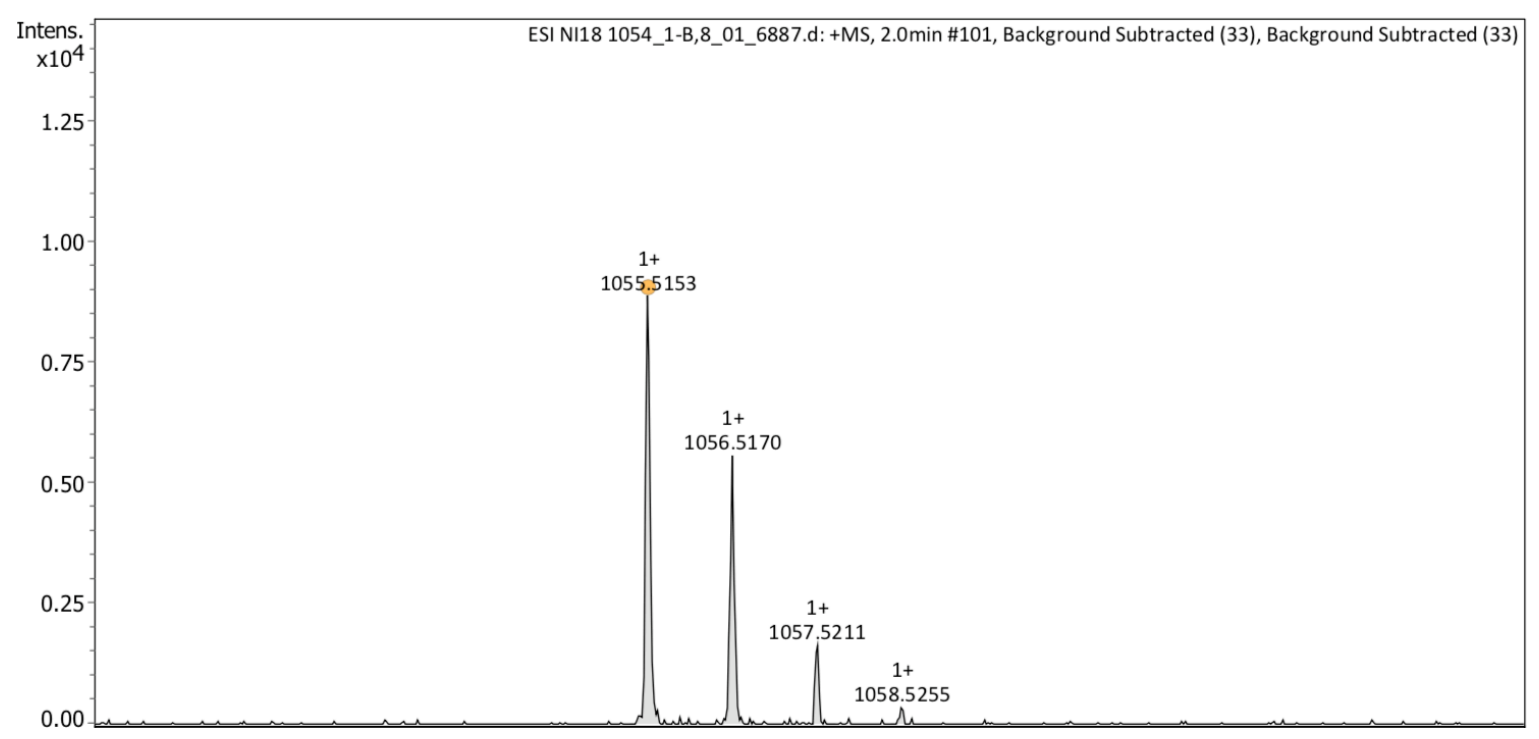

Figure S12 High resolution mass spectrometry (HR-MS) analysis of CPx-His. 


\section{Epifluorescence microscopy of CPx nanosheets}
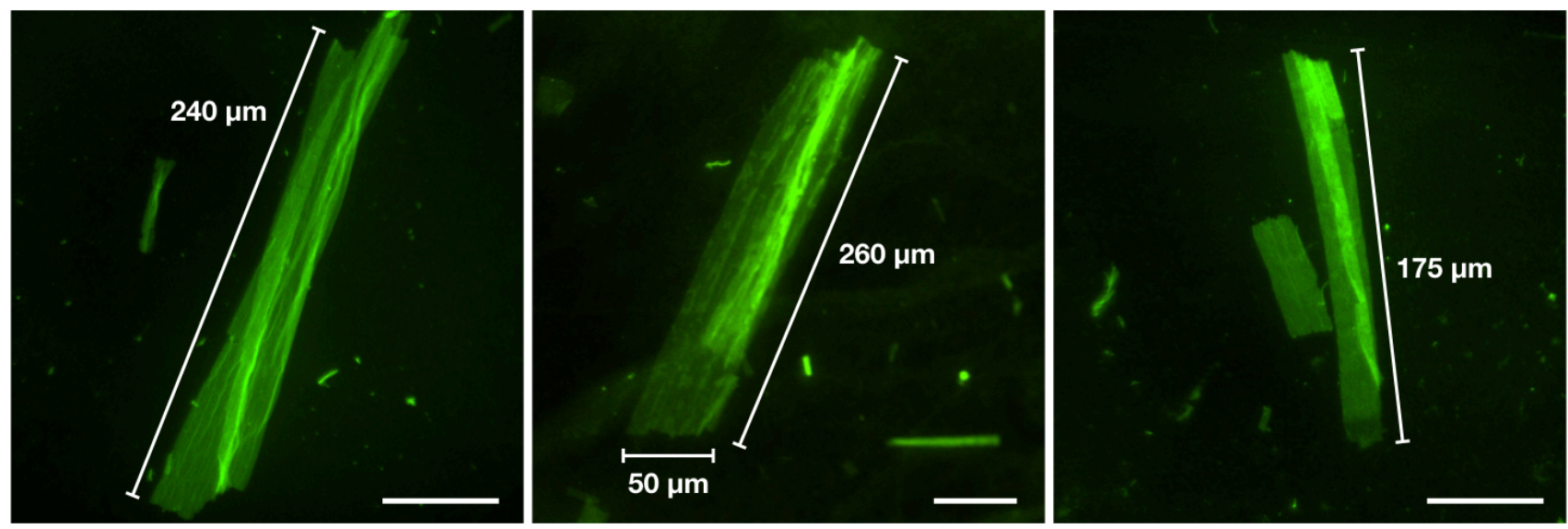

Figure S13 Epifluorescence micrographs of CPx nanosheets. Scale bars $=50 \mu \mathrm{m}$.

\section{Scanning-transmission electron microscopy (STEM) of CPx nanosheets}
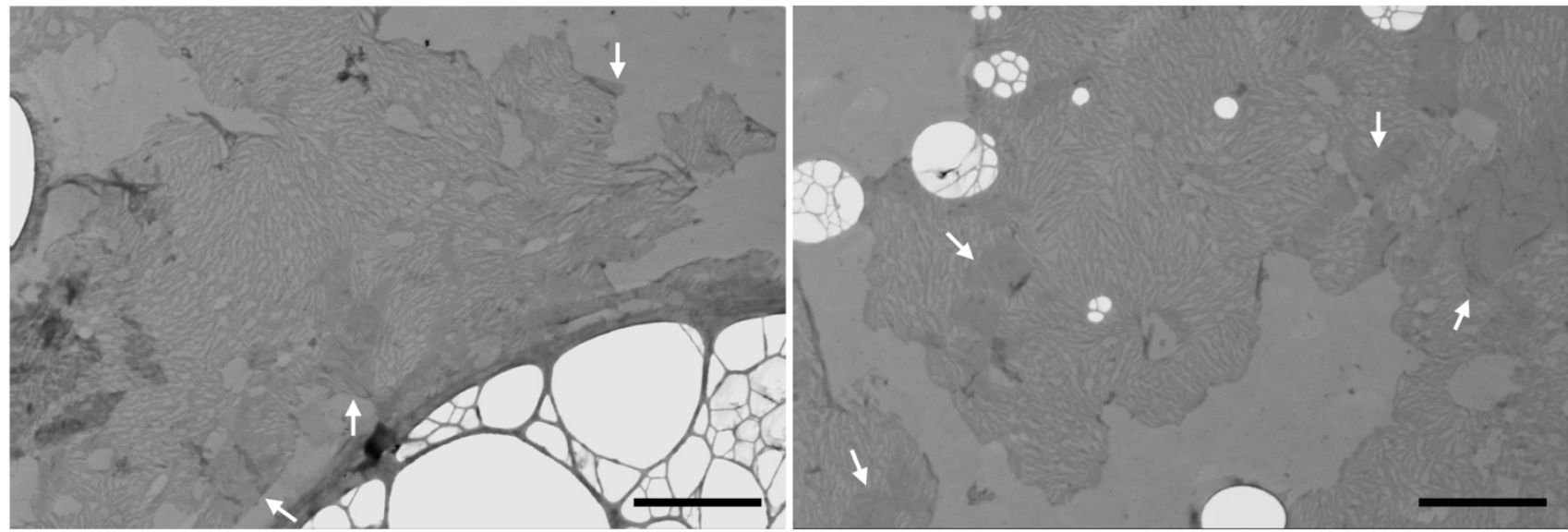

Figure S14 Scanning-transmission electron microscopy (STEM) of damaged CPx nanosheets. Aligned nanotubes can be found only on defined areas of the grid next to remaining sheet fragments (see arrows), suggesting the disassembly of sheets into their tubular building blocks. Scale bars $=1 \mu \mathrm{m}$. 


\section{Sonication of CPx nanosheets: Epifluorescence and electron microscopy}
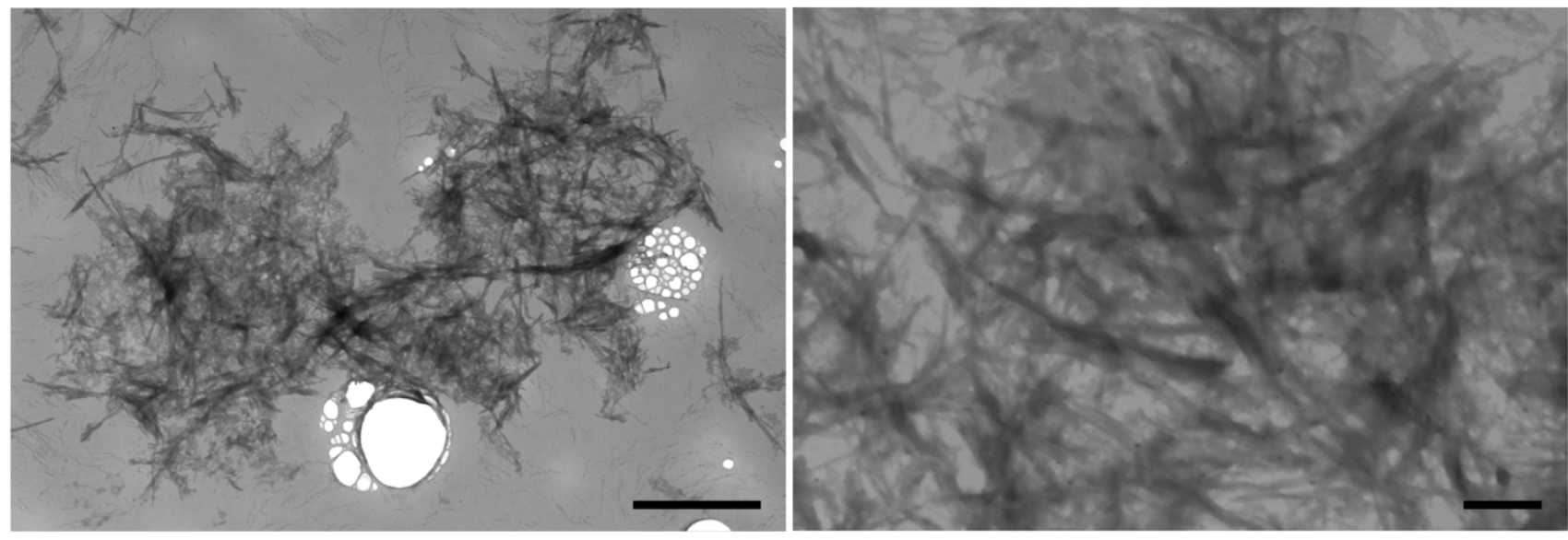

Figure S15 Scanning-transmission electron microscopy (STEM) of sonicated CPx nanosheets revealing their constituting nanotubes. Scale bars $=1 \mu \mathrm{m}$ (left) and $200 \mathrm{~nm}$ (right).
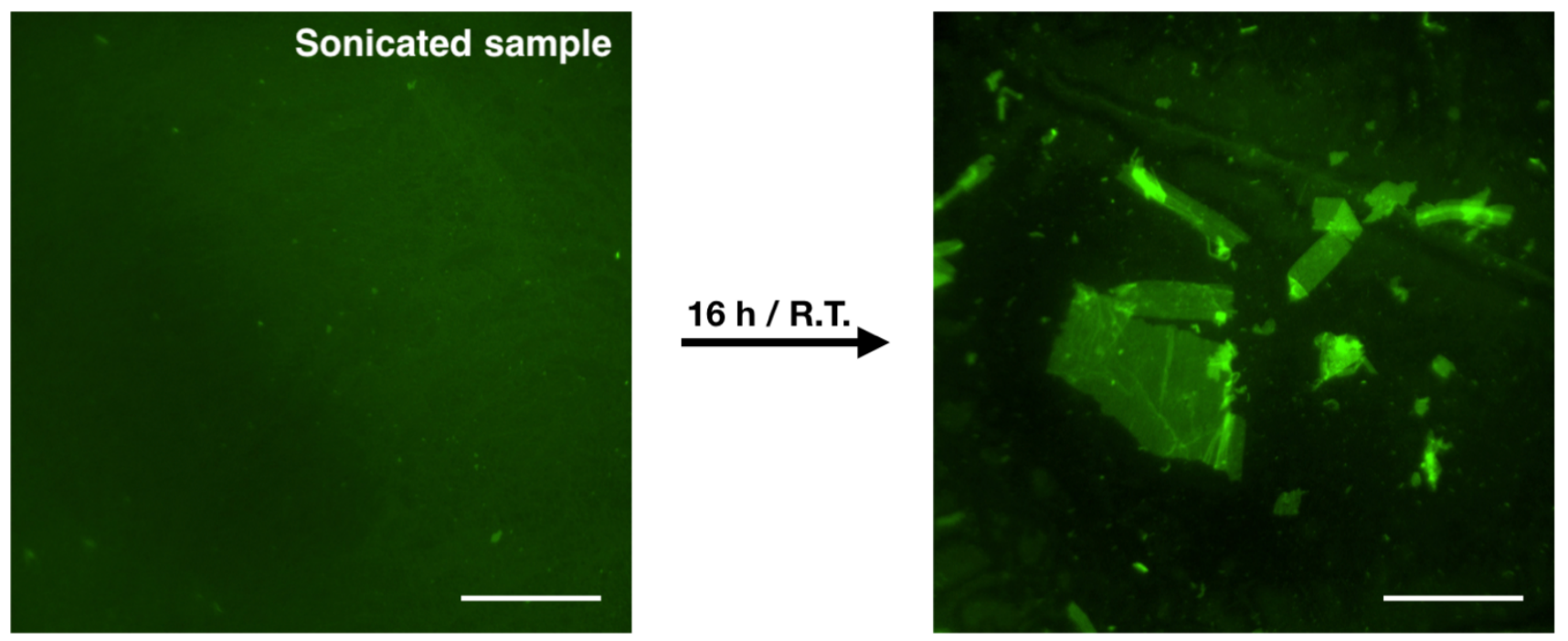

Figure S16 Epifluorescence micrographs of CPx nanosheets after sonication (left) and that same sample after $16 \mathrm{~h}$ (i.e. overnight) of recovery at room temperature (R.T.). Scale bars $=50 \mu \mathrm{m}$. 


\section{Annealing of CPx nanosheets: Electron microscopy}
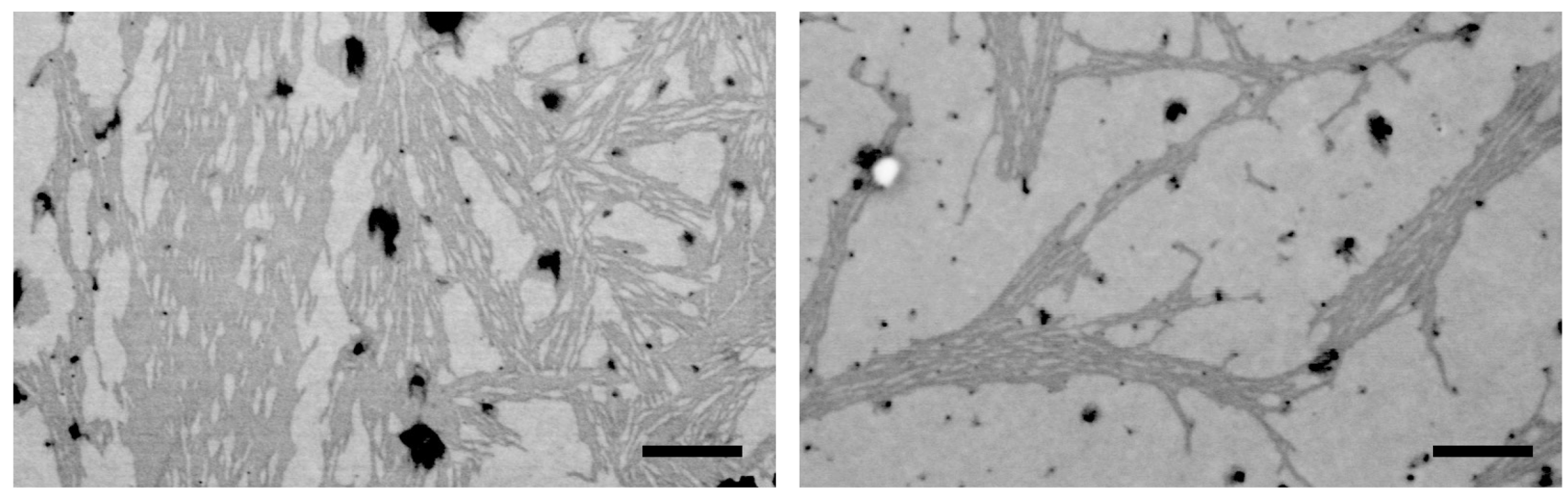

Figure S17 Scanning-transmission electron microscopy (STEM) of CPx samples (100 $\mu \mathrm{M})$ heated at $80^{\circ} \mathrm{C}$ for $1.5 \mathrm{~h}$. Scale bars $=300 \mathrm{~nm}$.

13. Annealing of CPx nanosheets: Dynamic light scattering (DLS)
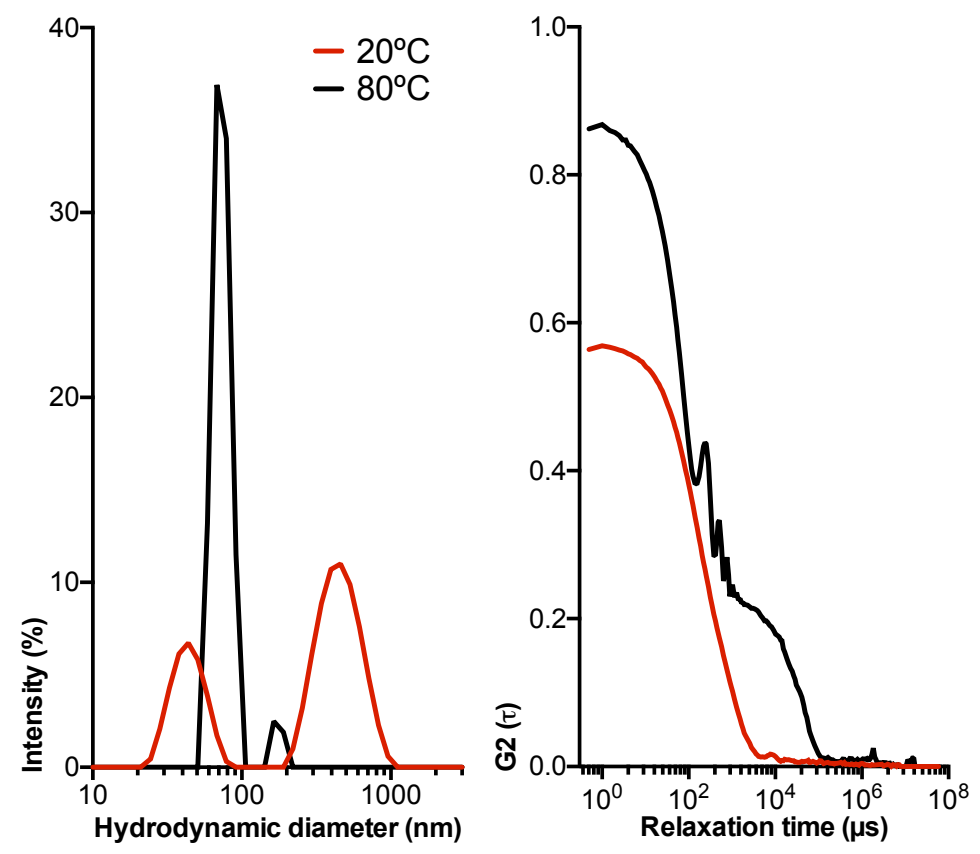

Figure S18 Dynamic light scattering (DLS) characterisation of CPx samples $(100 \mu \mathrm{M})$ at $80^{\circ} \mathrm{C}$ and $20^{\circ} \mathrm{C}$. Left: Size-Intensity plot. Right: Correlograms. 


\section{Exploration of self-assembling conditions of CPx nanosheets}
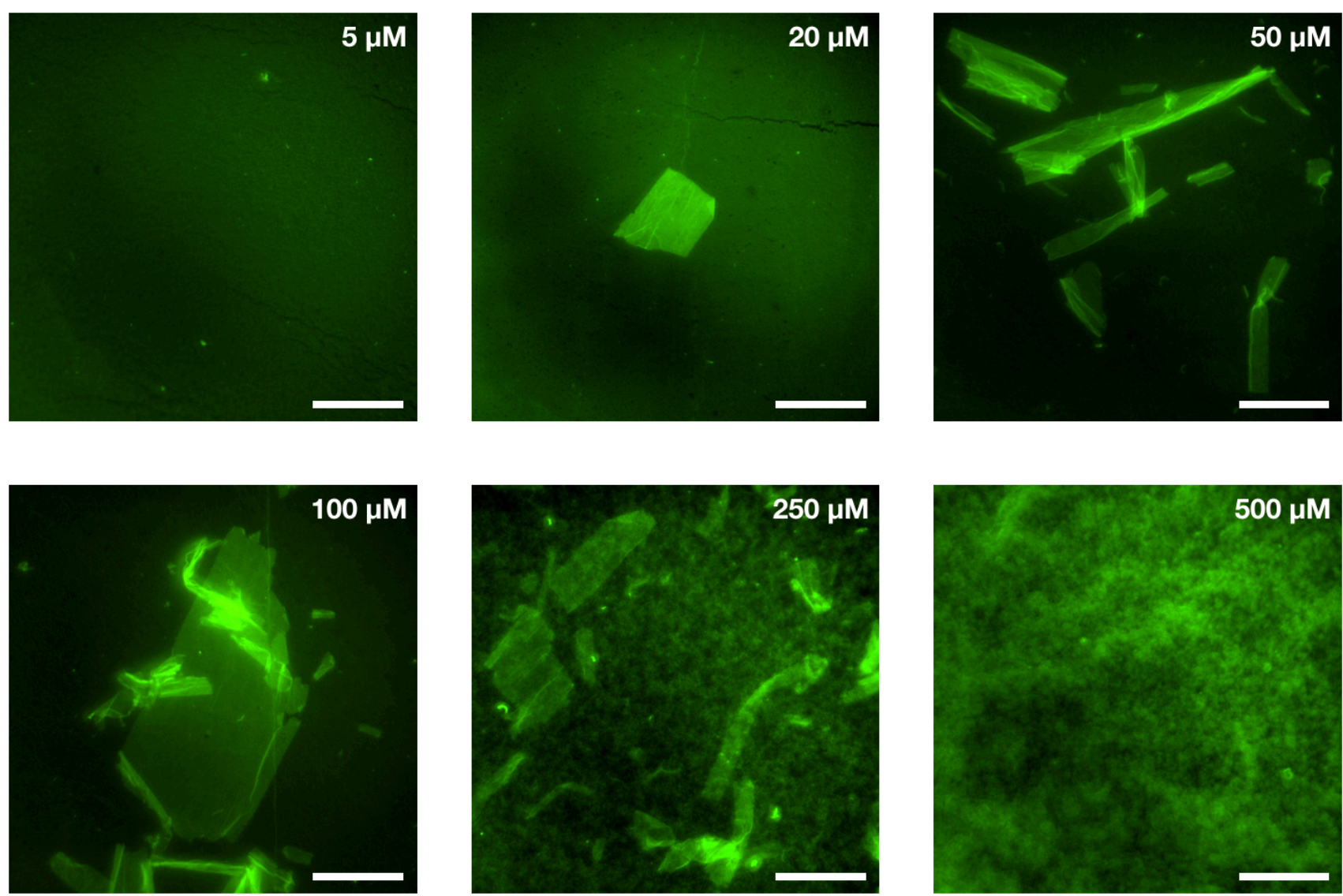

Figure S19 Effect of CPx concentration on nanosheet assembly. Epifluorescence micrographs of CPx samples prepared at different CPx concentrations (5-500 $\mu \mathrm{M}$, see insets). Scale bars $=50 \mu \mathrm{m}$. 

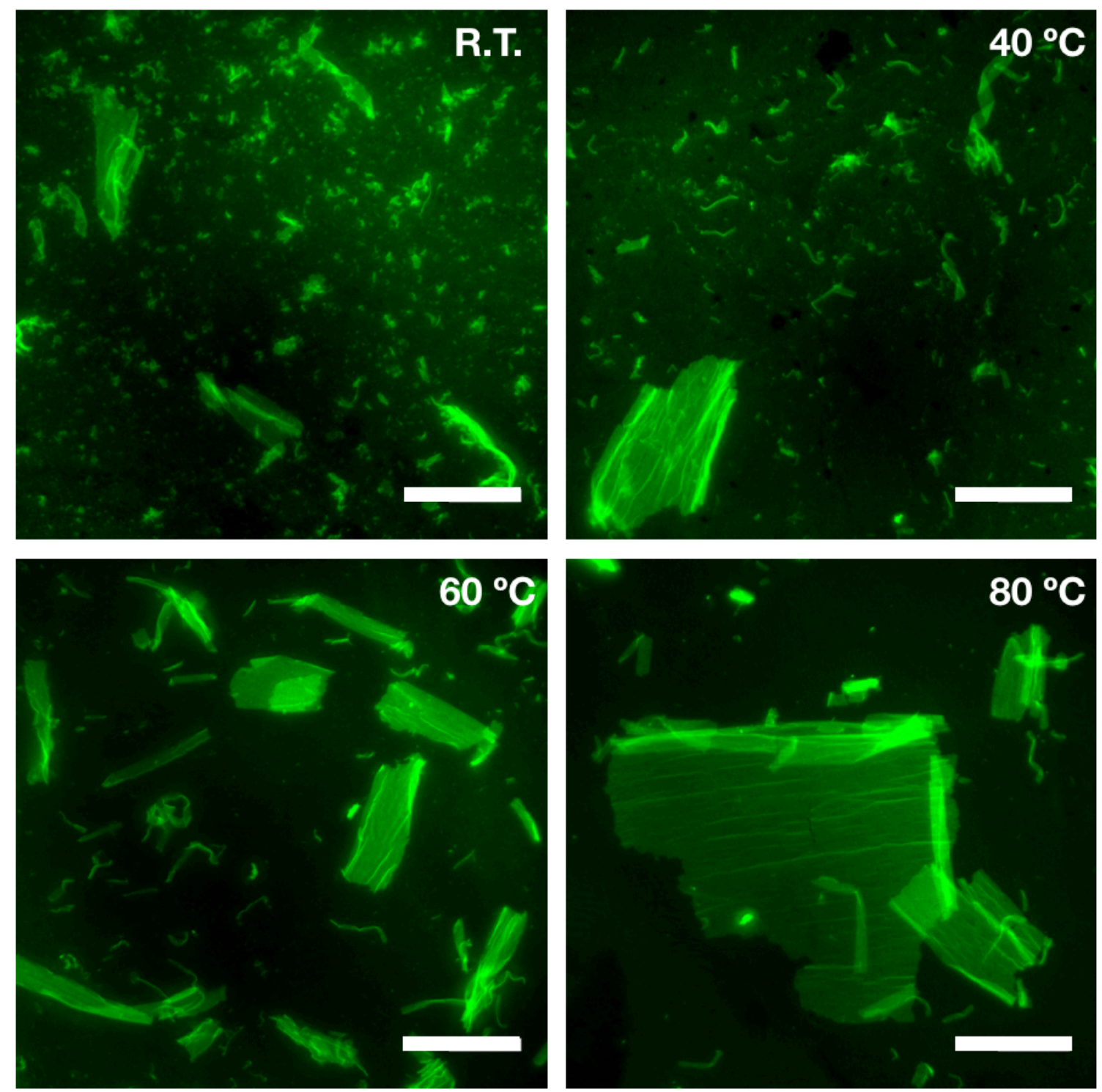

Figure S20 Effect of temperature on nanosheet assembly. Epifluorescence micrographs of CPX samples $(100 \mu \mathrm{M})$ annealed at different temperatures (see insets). R.T. = Room temperature. Scale bars $=50 \mu \mathrm{m}$. 


\section{Atomic force microscopy (AFM) of CPx nanosheets at pH 2.8}

Nanosheet height at pH 2.8 (Figure S22) matches that observed at pH 7.4 (Figure 4a).
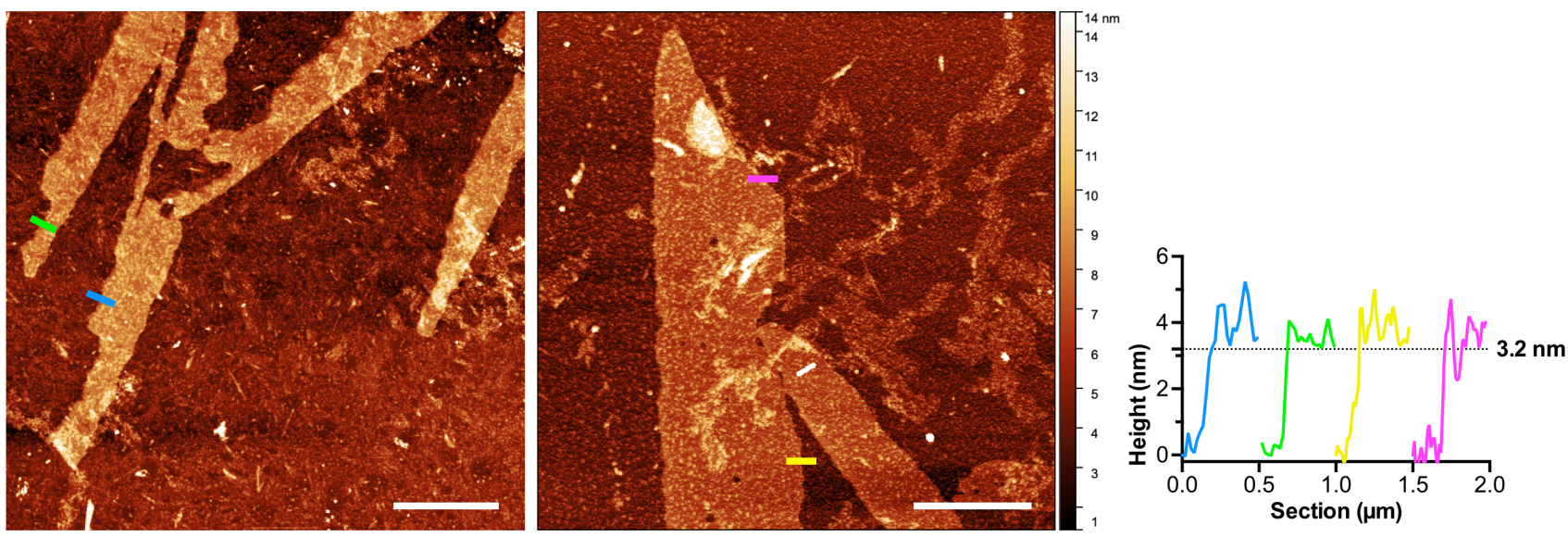

Figure S21 Atomic force micrographs and height profiles of CPx nanosheets annealed (i. $80^{\circ} \mathrm{C} / 1.5$ h; ii. R.T./1 h) at $\mathrm{pH}$ 2.8. Scale bars $=2 \mu \mathrm{m}$.

\section{Dynamic behaviour of $\mathrm{CPx}$ nanosheets in response to $\mathrm{pH}$ and temperature}

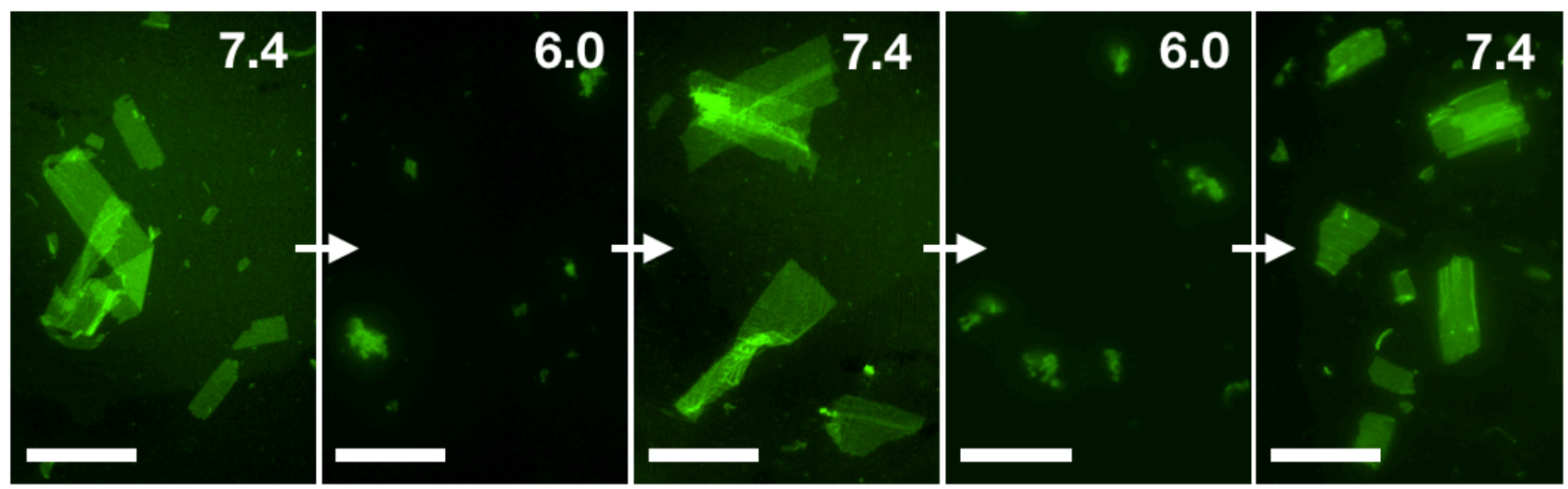

Figure S22 Epifluorescence micrographs of CPx solutions (100 $\mu \mathrm{M})$ sequentially adjusted between pH 6.0 and 7.4. All samples underwent a heating-cooling cycle (i. $80^{\circ} \mathrm{C} / 1.5 \mathrm{~h}$; ii. R.T./1 h) before imaging. Scale bars $=50 \mu \mathrm{m}$. 


\section{FT-IR analysis of CPx nanosheets}

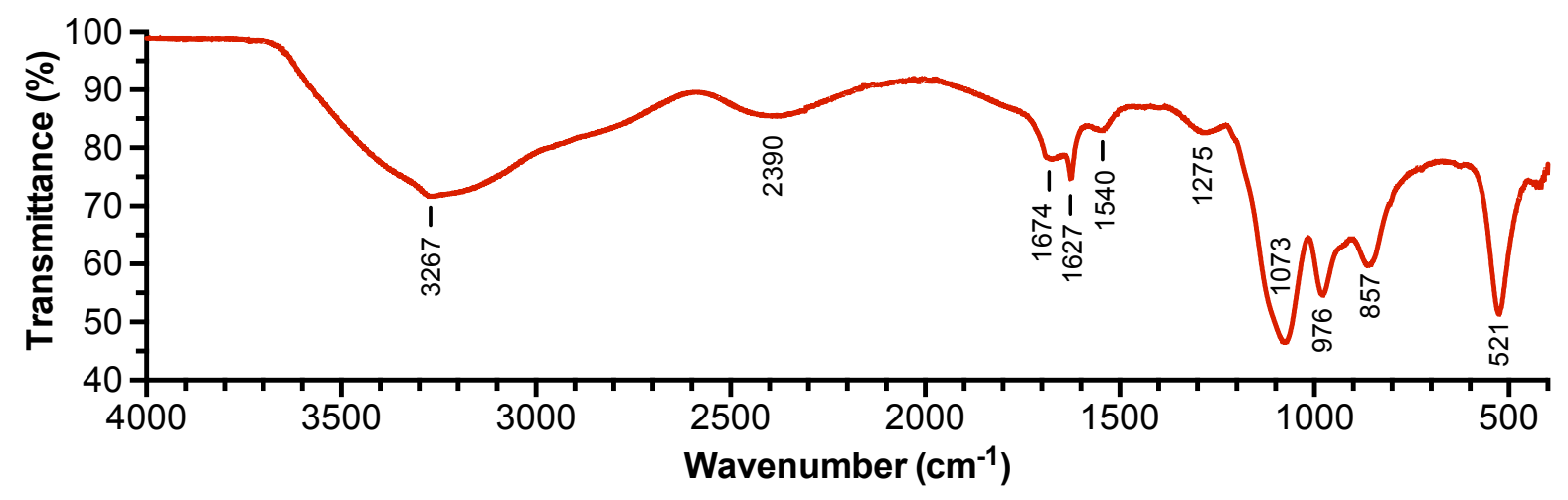

Figure S23 FT-IR spectrum of CPx nanosheets. Bands corresponding to the H-bonded backbones of cyclic peptides as $\beta$-sheets are indicated with a black line between the spectrum and their wavenumber. The sample was drop-cast ( $5 \times 10 \mu \mathrm{L})$ and dried on the ATR crystal for analysis.

\section{Circular dichroism (CD) analysis of CPx nanosheets}

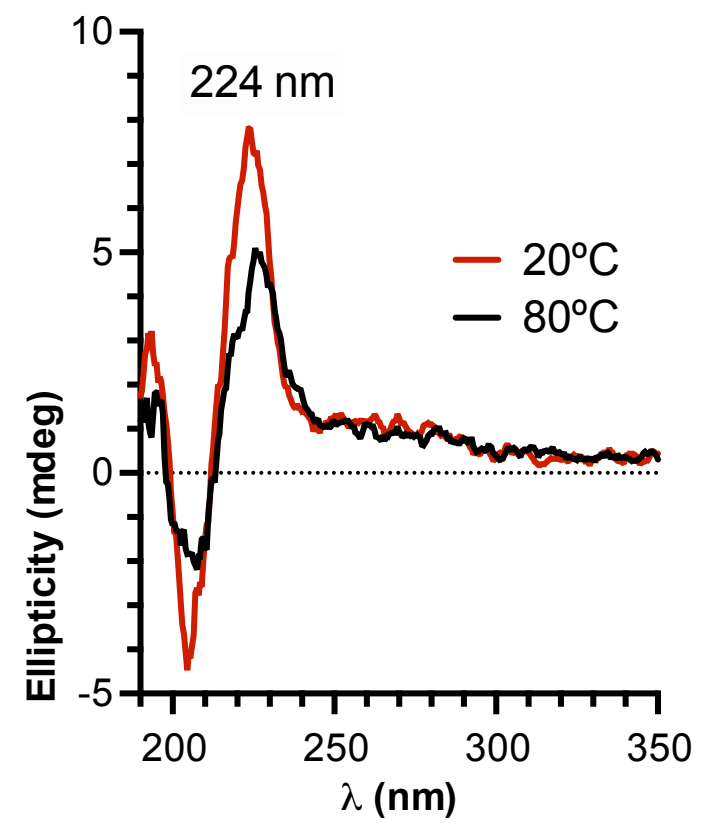

Figure S24 Circular dichroism (CD) spectrum of CPx nanosheets $(100 \mu \mathrm{M})$ at a pH of 7.4 recorded at $20^{\circ} \mathrm{C}$ and $80^{\circ} \mathrm{C}$. 


\section{Imaging of peptide controls (CPxAla, CPx-Glu and CPx-His)}
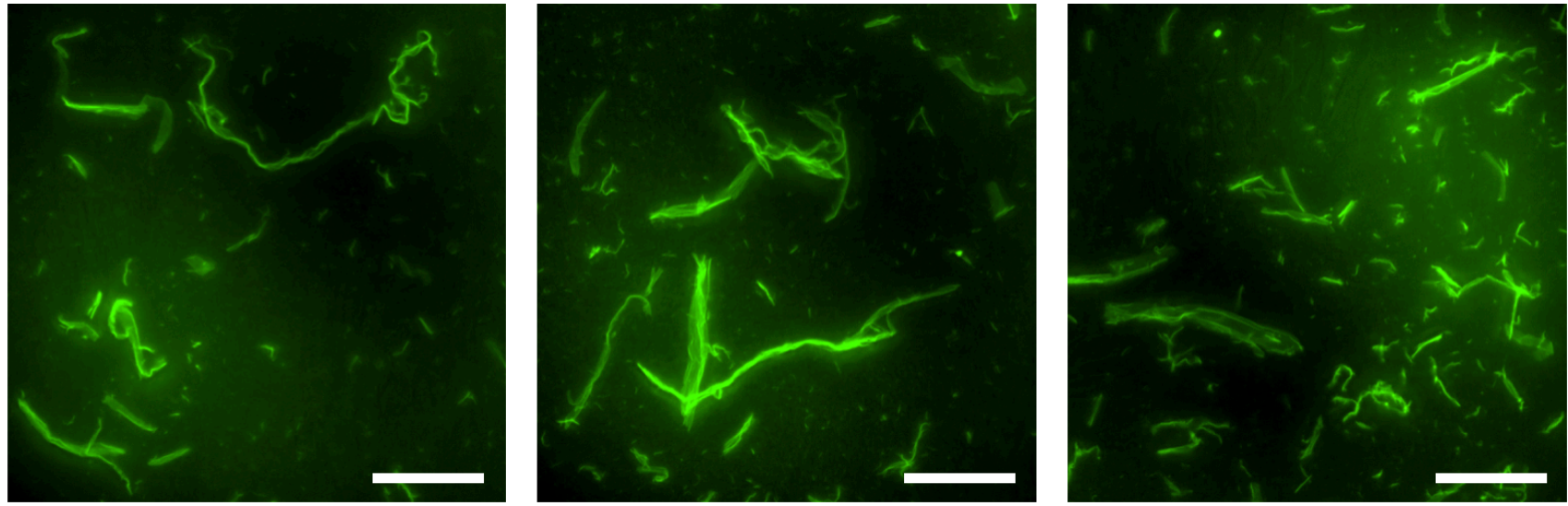

Figure S25 Epifluorescence micrographs of CPxAla solutions (100 $\mu \mathrm{M})$ prepared in $20 \mathrm{mM}$ phosphate buffer at pH 7.4. Samples underwent a heating-cooling cycle (i. $80^{\circ} \mathrm{C} / 1.5 \mathrm{~h}$; ii. R.T./1 h) before imaging. Scale bars $=50 \mu \mathrm{m}$.
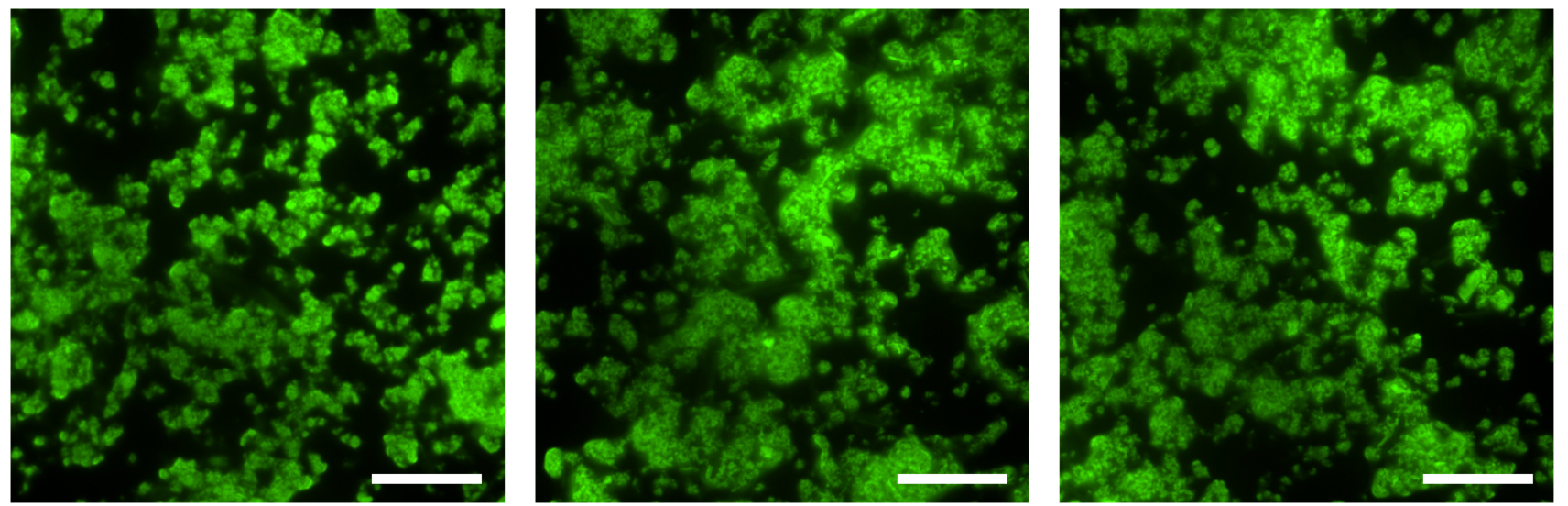

Figure S26 Epifluorescence micrographs of CPx-Glu solutions $(100 \mu \mathrm{M})$ prepared in $20 \mathrm{mM}$ phosphate buffer at pH 7.4. Samples underwent a heating-cooling cycle (i. $80^{\circ} \mathrm{C} / 1.5 \mathrm{~h}$; ii. R.T./1 h) before imaging. Scale bars $=50 \mu \mathrm{m}$. 

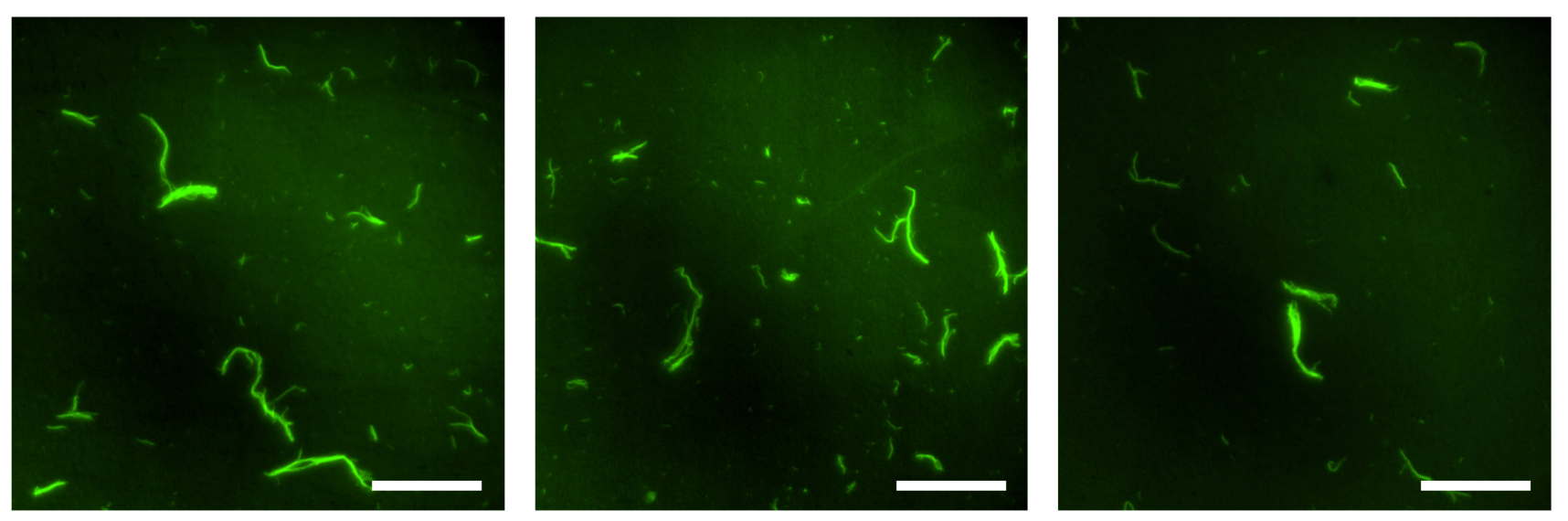

Figure S27 Epifluorescence micrographs of CPx-His solutions $(100 \mu \mathrm{M})$ prepared in $20 \mathrm{mM}$ phosphate buffer at pH 7.4. Samples underwent a heating-cooling cycle (i. $80^{\circ} \mathrm{C} / 1.5$ h; ii. R.T./1 h) before imaging. Scale bars $=50 \mu \mathrm{m}$. 